\title{
Establishing criteria for the management of tephritid fruit fly outbreaks
}

\author{
Michael D. Ormsby* (i)
}

\begin{abstract}
Tephritid fruit flies (Diptera; Tephritidae) represent a group of insects that include some of the most economically important pests in horticulture. Because of their economic importance, the financial impacts of an incursion of tephritid fruit flies into a new area can often result in restrictions to trade. The economic impacts of any trade restrictions imposed by importing countries are confounded by the current absence of consistent and accepted criteria for the strength and extent of any trade restrictions and declaring the end of an incursion. The author has developed models that can be used to establish criteria for the management of tephritid fruit fly outbreaks as outlined in international standards. A model enables criteria on when to recognise an incursion has occurred and establish export restrictions. Another model determines what area or radius an export restriction zone (ERZ) should cover. And a third model establishes criteria for the conditions required to enable an ERZ to be rescinded and the area's pest free status reinstated. The models rely primarily on fruit fly biology and the effectiveness of surveillance trapping systems. The adoption of these proposed criteria internationally for establishing a control system and responding to fruit fly outbreaks would provide considerable economic benefits to international trade. Additionally, these criteria would enable countries to make more informed cost-benefit decisions on the level of investment in fruit fly control systems that better reflects the economic risks fruit flies represent to their economy.
\end{abstract}

\section{Background}

Tephritid fruit flies (Diptera: Tephritidae) represent a group of insects that include some of the most economically important pests in horticulture. There are an estimated 4,000 species of tephritid fruit flies world-wide, but only around an estimated 350 are considered potentially economically significant (Plant Health Australia, 2016), and around 70 of notable economic importance (Garcia 2009; Vargas et al. 2015; Qin et al. 2015; Doorenweerd et al. 2018). The incursion of a tephritid fruit fly species that is of notable economic importance into a new area can often result in restrictions to trade. The economic impacts of any trade restrictions imposed by importing countries are confounded by the absence of consistent and accepted criteria for the degree and

*Correspondence: Michael.Ormsby@MPI.govt.nz

Ministry for Primary Industries, PO Box 2526, Wellington 6140, New Zealand duration of any trade restrictions. For example, differences between countries in the size of the area upon which export restrictions are imposed (the export restriction zone or ERZ) increases the transaction costs to exporters as they are forced to implement multiple layered compliance systems (Dominiak and Fanson 2014) (see Table 1 for examples).

Horticultural producers and exporters worldwide require pre-agreed generic bilateral market access conditions in the event of future fruit fly incursions, to significantly reduce the economic impact of trade restrictions on tephritid fruit fly incursions. Substantial benefits would accrue if one arrangement was accepted by all. However, sound scientific reasoning is required to support the development of a framework that can be applied across the range of fruit fly species and potential outbreak scenarios. A good scientific basis is required by trading partners to agree in advance to the parameters of any trade response. 
Table 1 Difference amongst countries in criteria to declare a fruit fly incursion, the size of the area to be treated and for declaring eradication (c 2015)

\begin{tabular}{|c|c|c|c|}
\hline Criteria & $\begin{array}{l}\text { New Zealand system } \\
\text { (for Bactrocera tryoni and } \\
\text { Bactrocera dorsalis) }\end{array}$ & $\begin{array}{l}\text { Australian system } \\
\text { (for Bactrocera tryoni) }\end{array}$ & $\begin{array}{l}\text { Californian system } \\
\text { (for Bactrocera dorsalis) }\end{array}$ \\
\hline Trigger for a fruit fly incursion & $\begin{array}{l}\text { Detection of any juvenile life stage } \\
\text { found in locally ground fruit or } \\
\text { gravid female fly for eradication } \\
\text { OR } \\
\text { Detection of } 1 \text { or more* adult male } \\
\text { flies for eradication } \\
\text { * depends on the circumstance of the } \\
\text { finds }\end{array}$ & $\begin{array}{l}\text { Detection of any juvenile life } \\
\text { stage found in locally ground } \\
\text { fruit or gravid female fly for } \\
\text { eradication } \\
\text { OR } \\
\text { Detection of } 5 \text { or more adult } \\
\text { male flies in } 14 \text { days within } \\
1 \mathrm{~km} \text { radius }\end{array}$ & $\begin{array}{l}\text { Detection of any juvenile life stage } \\
\text { found in locally ground fruit or gravid } \\
\text { female fly for eradication } \\
\text { OR } \\
\text { Detection of } 6 \text { (urban) or } 8 \text { (commer- } \\
\text { cial) adult (non-gravid) flies within } \\
28 \text { days and } 4.8 \mathrm{~km}\end{array}$ \\
\hline Size of $E R Z$ & $\begin{array}{l}\text { Depends on the circumstance of the } \\
\text { eradication and largely dictated by } \\
\text { trading partners }\end{array}$ & $15 \mathrm{~km}$ radius & $8.2 \mathrm{~km}$ radius \\
\hline Declaring a Successful Eradication & $\begin{array}{l}\text { Depends on the circumstance of the } \\
\text { eradication and largely dictated by } \\
\text { trading partners }\end{array}$ & $\begin{array}{l}\text { The greater period of trapping } \\
\text { with zero flies detected (of any } \\
\text { life stage) within the } E R Z^{@} \text { : } \\
\text { One generation (egg to egg) } \\
\text { plus } 4 \text { weeks } \\
\text { OR } \\
12 \text { weeks } \\
\text { (No minimum trapping density } \\
\text { is specified) }\end{array}$ & $\begin{array}{l}\text { Three fruit fly generations (egg to egg) } \\
\text { with zero flies detected (of any life } \\
\text { stage) } \\
\text { (No minimum trapping density is } \\
\text { specified) }\end{array}$ \\
\hline
\end{tabular}

Two fruit fly species in the Bactrocera genus are considered internationally amongst the most economically important (Schutze et al. 2015; Doorenweerd et al. 2018; Dominiak and Fanson 2020). Queensland fruit fly Bactrocera tryoni (Froggatt) (Diptera: Tephritidae) is the most important fruit fly pest in eastern Australia (Dominiak et al. 2015; Plant Health Australia 2016) and is currently known to infest more than 100 native and introduced hosts (Hancock et al. 2000). Oriental fruit fly Bactrocera dorsalis (Hendel) (Diptera: Tephritidae) is known for its extreme polyphagy, with over 209 recorded larval hosts across 51 plant families (Clarke et al. 2005).

Any internationally agreed framework for the management of these fruit flies would need to align with the international standard FAO (2016). This international standard provides a high-level framework for the establishment or reinstatement and maintenance of Pest Free Areas (PFA) for tephritid fruit flies. The international standard outlined three actions that occur when a PFA is invaded by a tephritid fruit fly. Here I present models that can be used to establish criteria for the three actions outlined in FAO (2016) (Fig. 1), namely:

1. Criteria for determining when an outbreak has occurred; the number of adult flies that are detected before an ERZ is implemented and the pest-free status of the localised area is suspended (often referred to as the trigger);

2. Criteria for determining the size (area or radius) of the eradication area and therefore the ERZ, out- side of which any host material grown would still be deemed to be within a pest free area; and

3. Criteria for the conditions required to enable an ERZ to be rescinded and the area's pest free status reinstated.

\section{Criteria for the fruit fly outbreak "trigger"}

FAO (2016) stated that for all fruit flies of economic importance the number of detected fruit flies that indicate a breeding population may exist in the area, and therefore trigger the need to establish an ERZ, is as follows:

a. Detection of any gravid female flies or any juvenile life stage (excluding immature (teneral) adults) not directly associated with imported produce, should indicate the need to establish an ERZ;

b. For fruit flies attracted to any of the (male) lures included in a fruit fly surveillance system, the detection of 2 or more male flies should be considered a potential outbreak (FAO 2016).

For the second trigger, the upper number of male fruit flies detected in lure-baited traps that indicates the need to establish an ERZ (the trigger number) needs to be resolved for each fruit fly species (see Meats 2014).

While criteria (a) is clear, for criteria (b), can we define "two or more fertile adults" more precisely to ensure any imposition of an ERZ is appropriate to the risk? The 


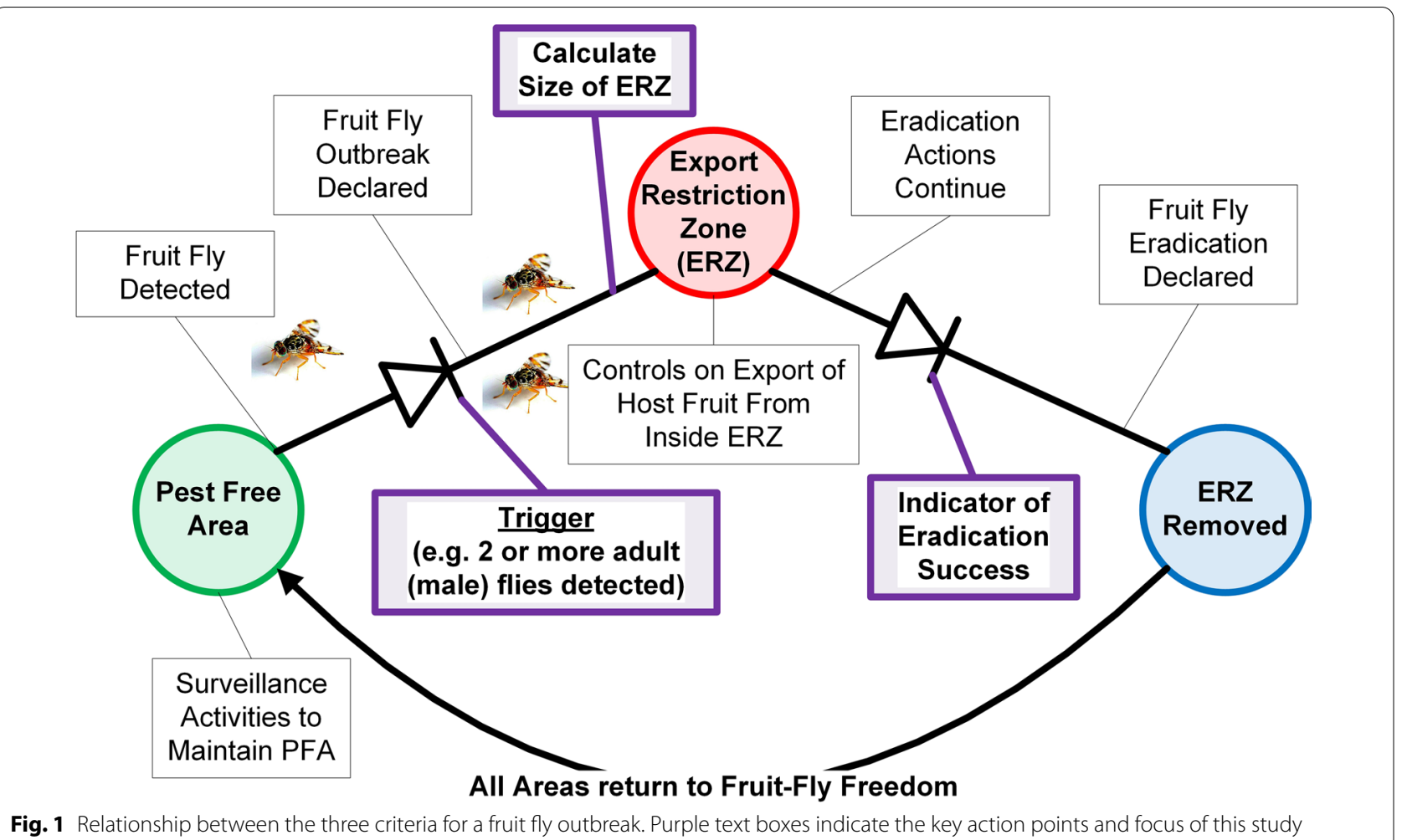

risk with regards to market access could be described as being: The unacceptable likelihood of there being a population of fruit fly (present in the area) that is of sufficient size to result in host material becoming infested, being exported, establishing a population in an export market, and causing unwanted impacts. For the purposes of this paper, the market access risk will be simplified to: The unacceptable likelihood of there being a breeding population of fruit fly present in the area.

The size of the population of flies constituting a risk to export markets, otherwise stated in this paper as the 'breeding population size', will therefore need to be determined for each fruit fly species. The 'breeding population size' can be considered the minimum number of fruit flies in an area at which mating is likely to occur and potentially result in eggs being laid in host material (e.g. based on the probability of success). This is similar to the concepts of 'Allee threshold' used in population dynamics, as well as the 'minimum viable population size' used in conservation ecology (Tobin et al. 2011).

\section{Criteria for the size of the ERZ}

The aim here is to determine a scientifically justified size for the ERZ around the detection site for the population of flies of each fruit fly species that may be present at the time of detection. FAO (2016) stated that the "eradication area should cover the infested area. In addition, a buffer zone should be established in accordance with this standard, and as determined by delimiting surveys, taking into account the natural dispersal capability of the target fruit fly species, its relevant biological characteristics, and other geographic and environmental factors." The combined eradication area and buffer zone can be considered the ERZ; movement of all host material should be restricted within this area.

FAO (2016) further stated that a "circle delimiting the minimum size of the eradication area should be drawn, centred on the actual target fruit fly species detection and with a radius large enough to comply with the above considerations".

Therefore, an ERZ is a circle on a map that is centred on the site of a fruit fly detection and encompasses an area that covers the natural dispersal capability of the target fruit fly species. The size of the ERZ can vary greatly between countries as is evident in Table 2 . An analysis of Australian B. tryoni trapping data found that a single fly of this species of fruit fly was unlikely to naturally disperse more than $1.5 \mathrm{~km}$ suggesting that the current $15 \mathrm{~km}$ infestation radius employed by Australia could be reduced substantially to 3 or $4 \mathrm{~km}$ (Dominiak and Fanson 2020). 


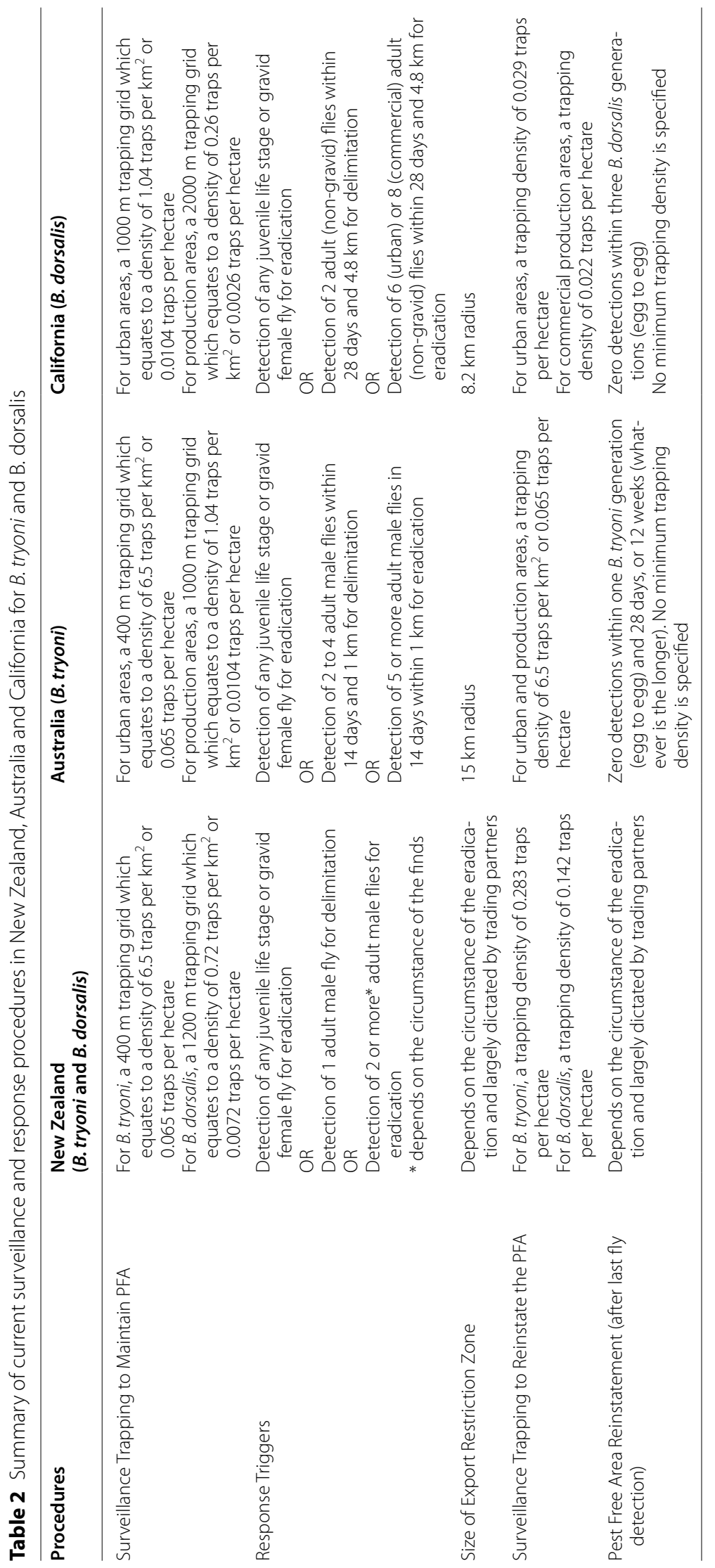




\section{Criteria for indicating eradication success}

The aim here is to establish the evidence threshold required to provide sufficient confidence that eradication has been successful and the ERZ can be removed. FAO (2016) stated that the eradication can be considered successful and the area declared free of the target fruit fly when there have been "no further detections of the target fruit fly species for a period determined by its biology and prevailing environmental conditions, as confirmed by surveillance".

The aim of this paper, therefore, is to provide a method of determining the criteria for the management of tephritid fruit fly outbreaks as outlined in international standards.

\section{Methods}

\section{Model development}

To estimate aspects of establishing and removing fruit fly ERZs, my model relies primarily on aspects of fruit fly biology and epidemiology along with a measure of lure + trap efficacy referred to as the effective sampling area (ESA). Turchin and Odendaal (1996) refer to the ESA as both a translation coefficient between population density and insect captures in a single trap, and the area by which we need to divide trap catch in order to obtain an estimate of population density. This relationship between trap catch and insect density is particularly useful when considering the effectiveness of surveillance and population delimitation programmes.

The ESA is (approximately) equal to the proportion of trappable individuals that are captured (over a set period of time) divided by the trapping density (Kean 2015a).

Equation 1: Calculating the effective sampling area (ESA)

$$
E S A \approx \frac{\text { CaptureProportion }}{\text { TrappingDensity }}
$$

The ESA can be estimated for each fruit fly species using published records of fruit fly release and recapture rates into areas that contain trapping grids of a known density (traps/ha). The ESA will vary between fruit fly species, therefore the requirements for the ERZ will also vary between fruit fly species. Additionally, the ESA may vary with habitat, weather, season, lure age, etc., but the derived values are assumed to cover the range of conditions likely to be encountered in urban and production environments.

A survey from 2002 to 2010 of the use of the ' 5 male files trapped over two weeks' trigger used by Australia to declare outbreaks of B. tryoni identified 439 incursions (detections) of which 48 (10.9\%) achieved the 5-fly trigger and were declared as outbreaks. The remaining 391 incursions $(89.1 \%)$ were not declared as outbreaks, and all subsequently died out without intervention (Dominiak and Fanson 2014). These results indicate that the 5-fly trigger for B. tryoni has ensured all potential outbreaks were responded to appropriately. My initial calculations of the trigger number for $B$. tryoni using the conservative value for the ESA ( $0.5 \mathrm{ha}$ ) indicated that the detected fly trigger number would be ' 1 ' over a period longer than 2 weeks. I wanted to ensure the outputs of the model aligned more closely with the observed situation in Australia, so I have used the median estimated value for ESA $\left(E A_{\text {med }}\right)$ as a closer approximation of the true ESA value.

I used published data to estimate the ESA of standard lure-based traps, as used in fruit fly surveillance programmes, for the two species of interest. When using a cue-lure trapping lure, I calculated that the ESA for B. tryoni was between 0.5 and 2.5 ha, with a median of 1.5 ha over a two-week period. When using a methyl eugenol trapping lure, I calculated that the ESA for $B$. dorsalis was between 5 and 12 ha, with a median of 9 ha over a two-week period. Full details of this are given in the Supplementary information. Other authors have calculated the ESA for B. tryoni at 0.214 ha per day using one data source converted to a daily catch rate, equating to an ESA of 3 ha over a two-week period (Stringer et al. 2017).

\section{Determining the total emergent population size}

Using area dispersion data for fruit fly species generated from single point release and area recapture studies, we can determine the proportion of the total fruit fly population that will be present in the highest densities. In all cases the highest density area is at the centre of the distribution, taken here as the central 1 hectare approximated as a $60-\mathrm{m}$ radius ( $\mathrm{r}$ ) circle (1.13 hectares). By increasing the number of lure responsive flies, we can determine the threshold for detecting a population that exceeds the threshold for an outbreak in that highest density area (centre $60 \mathrm{~m}$ circle (1.13 hectares)) using Eq. 2.

Equation 2: Calculating the density of flies within a specified radius from a known fly population distribution

$$
D r=N_{t} x \frac{C_{r}}{A_{r}}
$$

where $D_{r}=$ the density of flies (per hectare) in the centre 60 metre radius ( $r$ ) of the site of population emergence. $\mathrm{N}_{\mathrm{t}}=$ the number of detectable (male) flies assumed to be in the area, which can be taken as the number of invading or emerging male flies in the area. $\mathrm{C}_{\mathrm{r}}=$ The proportion of the total fruit fly population present in the centre 60 metre radius ( $r$ ), based on results from single point release and area recapture studies. $A_{r}=$ the area (ha) of the centre 60 metre radius ( $r$ ) (1.13 hectares). 


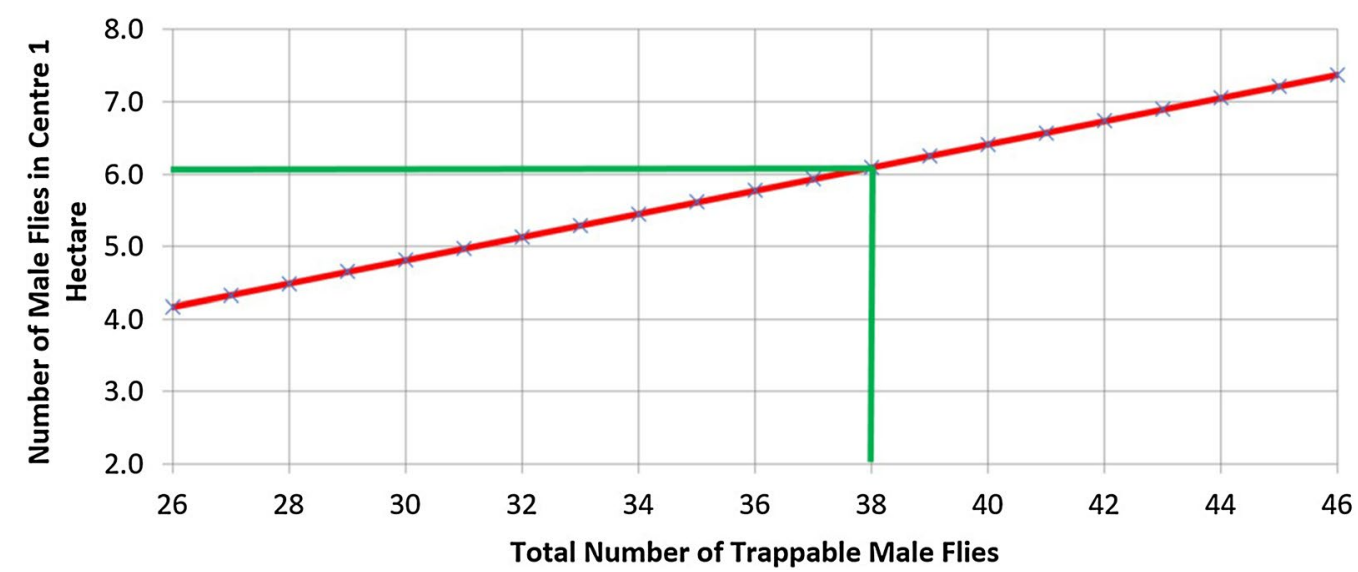

Fig. 2 Determining the population of male flies in a region required to exceed the founder population density in the centre of the outbreak. Red line is the estimated total number of male files present ( $x$ axis) with a given number of male flies in the centre 1 hectare. Green lines indicate the founder population density given a founder population size of 6 male flies

The results derived from Eq. 2 applied to example data calculated from another fruit fly (e.g. Ceratitis capitata) are provided in Fig. 2. In this example the number of male flies in any 1-hectare area considered sufficient to morethan-likely result in an establishment event (the founder population size) is 6 flies (e.g. the minimum number of files required to establish a population).

From Fig. 2 it is apparent that based on this example a founder population size of 6 flies, a total population of 38 adult male flies or more may result in a density of flies at the centre of the outbreak that exceeds that founder population size. The breeding population size for this example would therefore be taken to be 38 adult male files, or 76 male and female adult flies assuming the sex ratio is $1: 1$.

\section{Analysis of Triggers for Initiating an Export Restriction Zone}

If we know the size of the population of flies in an area that would be a risk to export markets (the breeding population size), we can calculate the number of flies we would be most likely to detect at a given detection probability (sensitivity of the surveillance trapping system). I assumed that capture is random, therefore the probability of trapping a certain number of flies in an area over a set period, based on a predetermined existing population, can be calculated using the binomial distribution (see Eq. 3). When more than one trap is deployed, I define trap cover as the total area sampled (number of traps $\times$ ESA) as a proportion of the total area (ESA $\times$ trap density). As trap cover will not equate to probability of capture if trap sampling areas overlap, for a range of trap configurations the expected proportion trapped, which is equivalent to the probability of capturing an individual, is closely approximated by an exponential function $(1-\exp (-$ trap cover $))$ or $\left(1-\exp \left(-E S A_{\text {med }} \times T_{d}\right)\right)($ Kean $2015 \mathrm{a}, \mathrm{b})$. This exponential function arises from the zero term of the Poisson distribution and appears in a wide range of studies on the detectability of organisms (see Kean 2015a, b).

Equation 3: The conditional probability of trapping exactly $f$ (male) flies given that there are $N_{t}$ detectable (male) flies in the area.

$$
P\left(f \mid N_{t}\right)_{f}=N_{t} ! \div\left(f !\left(N_{t}-f\right) !\right) \times\left(p^{f}(1-p)^{N_{t}-f}\right)
$$

where $P\left(f \mid N_{t}\right)_{f}=$ the conditional probability of detecting $f$ flies given the total number of detectable (male) flies in the area is $N_{t} f=$ the number of (male) flies detected in any of the traps within the area. $N_{t}=$ the number of detectable (male) flies assumed to be in the area, considered for the purposes of this paper to be the breeding population size. ! is the factorial function in statistics. $p=$ the probability of trapping a male fly, which equals $1-\exp \left(-E S A_{\text {med }} \times T_{d}\right)$ where $T_{d}$ is the surveillance trapping density (number of traps per hectare) and the $E S A_{\text {med }}$ is the median value for the effective sampling area for each fruit fly species and $\left(-E S A_{\text {med }} \times T_{d}\right)$ the trap cover.

Plotting the calculated values for $P_{f}$ (the probability) against $f$ (the number of flies detected) provides a distribution as shown by the example in Fig. 3 (where $N_{t}$ equals 52 and $p$ equals 0.1319 ) based on data from a fruit fly species with an ESA of 0.5 and 0.283 traps per ha. This curve should be interpreted as showing that, at a given probability of trapping male flies in an area $(p)$; when the population of the flies in an area is $N_{t}$ the probability $\left(P_{f}\right)$ is highest (at 16\%) you will detect either 6 or 7 flies over 


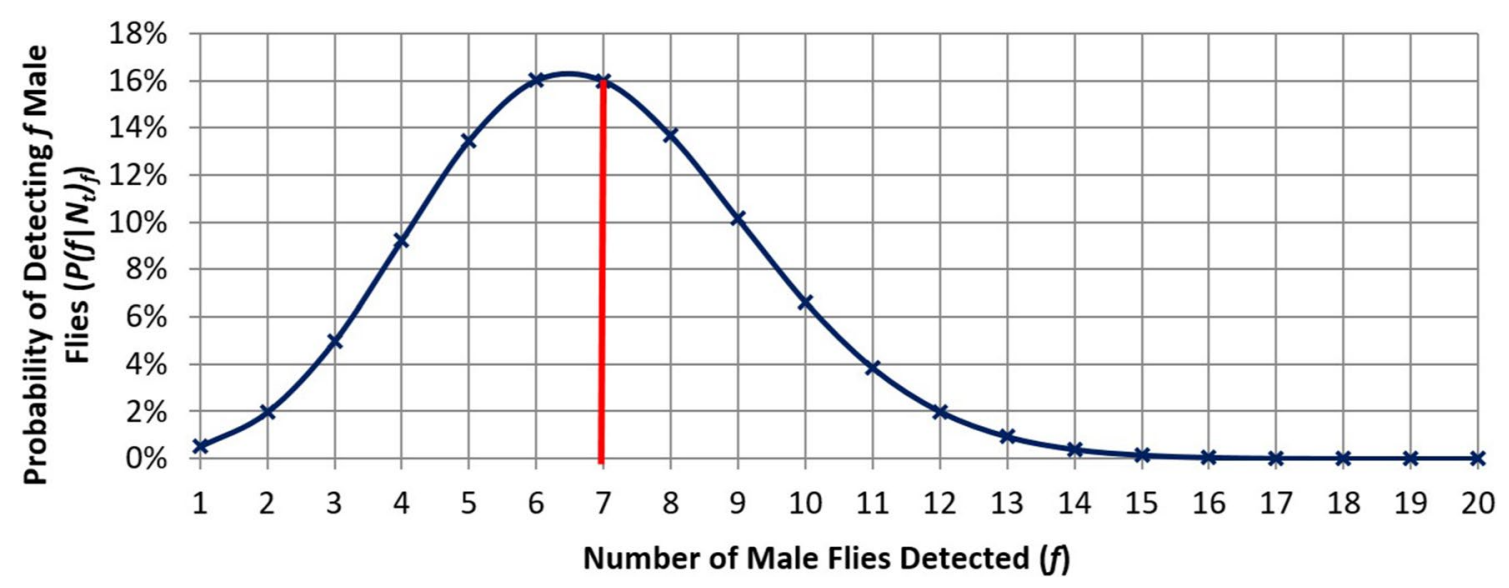

Fig. 3 An example of the probability of a specified trapping grid detecting $f$ male flies $\left(P\left(f \mid N_{t}\right)_{f}\right)$ from a breeding population size $\left(N_{t}\right)$ of 52 and a capture probability $(p)$ of 0.1319 . The red line indicates the number of flies detected with the greatest probability

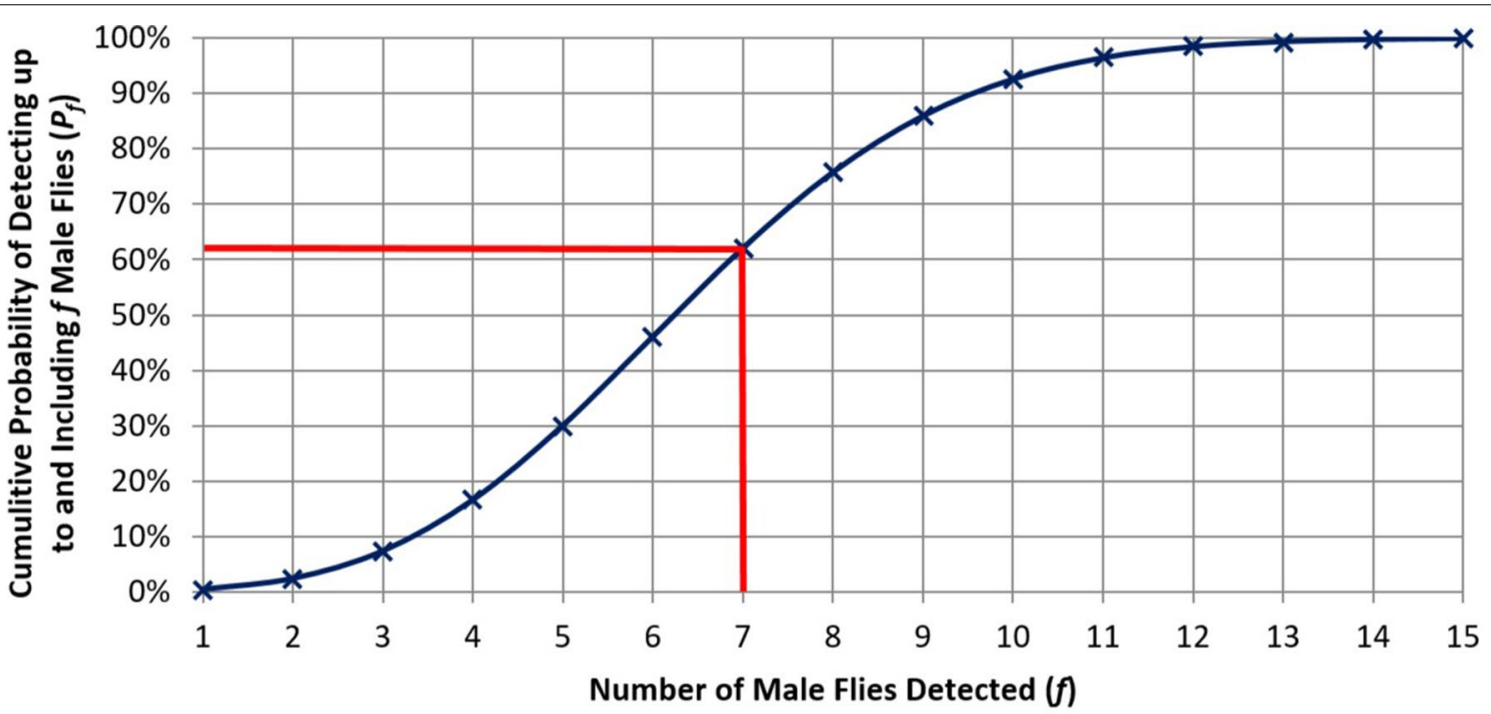

Fig. 4 An example of the cumulative probability of a specified trapping grid detecting $f$ male flies $\left(P_{f}\right)$ from a breeding population size $\left(N_{t}\right)$. The red line indicates the number of flies detected with the greatest probability

the duration of trapping i.e. there is a lower probability of detecting only one fly or 10 flies. The curve can also be plotted as a cumulative distribution, with the threshold being the number of flies detected above the $50 \%$ level $(7$ flies in this case).

Based on Fig. 3, we can estimate that, once seven (male) flies have been detected (the probability of catching 7 flies is $>0.5$ ), there is a greater than $50 \%$ probability that the total number of files in the area may exceed the breeding population size of 52 (in this example). For instance from the example provided in
Fig. 3 the trigger that would lead to establishing an ERZ for export markets would be seven male fruit flies (the red line) over the trapping period. An alternative method of plotting the same information is to use a cumulative probability for the vertical (y) axis (see Fig. 4).

The next questions to consider are:

a) Over what period the trigger is relevant (i.e. what is an appropriate trapping period), and

b) Over what area (radius) should any detections count toward the trigger? 


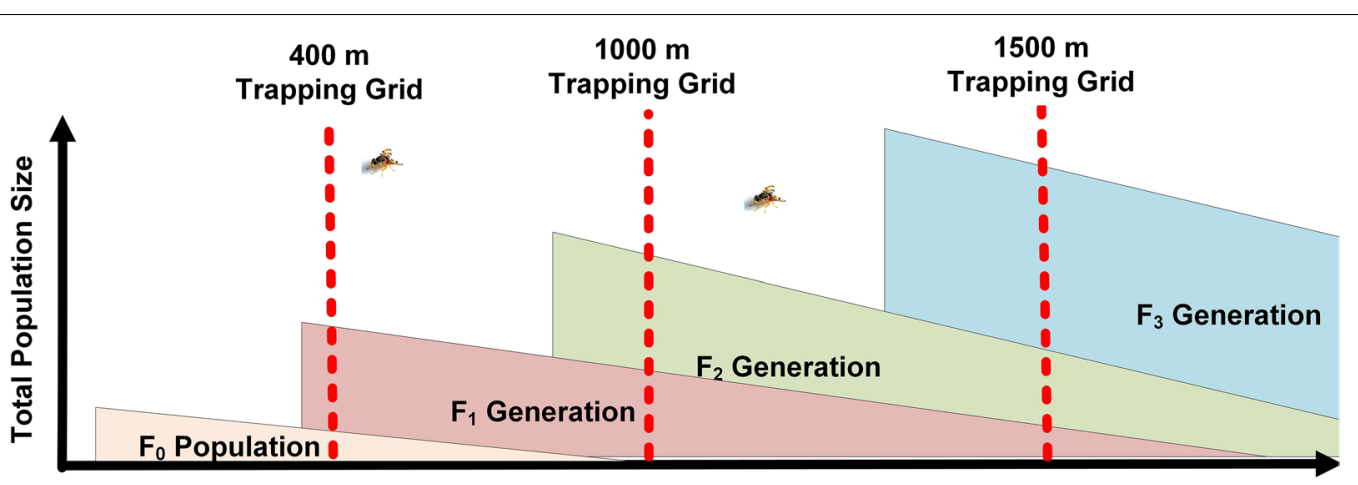

Time Before Detection of a Fruit Fly Population

Fig. 5 A conceptual example of how decreasing density of surveillance trapping grids may allow one or more fruit fly generations to occur prior to detection. Wedges indicate population size per generation over time

The ESA of the traps for each fruit fly species is based on the length of time the researchers recorded trap catches when gathering the data to estimate the trap sensitivity. However the majority of adult fruit flies survive or remain available to be trapped for only a relatively short time in optimal conditions (Vargas and Carey 1990; Yonow et al. 2004).

Therefore, I propose that the maximum period of fly capture (trigger) to determine if a breeding population exists in the area (and an ERZ is required) should be equivalent to the lesser of:

- The time it takes for a cohort of adult flies to decrease by $50 \%$ due to natural mortality, minus the duration of adult male fly maturation;

- OR

- The length of time the researchers recorded trap catches when gathering the data to estimate the level of trap sensitivity (the ESA) (assuming the researchers released mature flies) (e.g. 2 weeks).

Further, I propose that, to ensure a timely response to a potential establishment event is maintained, the time limit for the trigger should (where possible) be no more than two weeks (14 days) of the initial fruit fly detection. The area over which any detected fruit flies should be included in the trigger count is equivalent to the maximum area the fruit fly outbreak is likely to be contained.

\section{Calculating the size of an export restriction zone (ERZ)}

The ERZ is an area established for the purposes of providing assurance that host material grown and exported from outside the zone remain within a pest free area. Therefore, to be effective, the ERZ needs to delimit the probable area in which a breeding population may exist, if there is one present, with the assumption that we do not know the population distribution from the first few detections. From a risk-in-trade perspective, only juvenile (egg, larval) life stages are likely to move internationally, and the ERZ need only delimit the probable area within which a breeding population of flies may exist.

Generally, for small expanding populations the area occupied by a population increases as the number of individuals increase. Studies on the distribution of B. tryoni in Australia found that dispersal distances often followed an inverse-square relationship or analogous model (Meats 1998a). The more flies in a small incipient population, the greater the area covered by the population before the inverse-square becomes less than one (no flies present). Therefore, it is assumed that the size of the ERZ should be proportional to the number of flies estimated to be present at the time the zone is established. The greater the time between the fruit fly establishing a population in an area and the population being detected by the surveillance system (and an ERZ being established), the greater the size and spatial extent of the population likely to be present. This relationship between fruit fly population size and surveillance system (trapping grid) sensitivity is supported by Meats et al. (2003), who noted "Effective quarantine radii for suspension of fly-free status should be related to the number of flies trapped around the epicentre and the density of the trap array". An illustration of this relationship is provided in Fig. 5.

When no more than one generation $\left(\mathrm{F}_{1}\right)$ of fruit flies are likely to have begun emerging in an area (Fig. 6a), the relationship between the maximum dispersal distance (based on a probability distribution before the inverse-square becomes less than one) and the ERZ can be demonstrated by the diagram provided by Fig. $6 \mathrm{~b}$. In this example the single fly caught in the surveillance trap could have originated from a population of flies anywhere within the radius of the maximum 


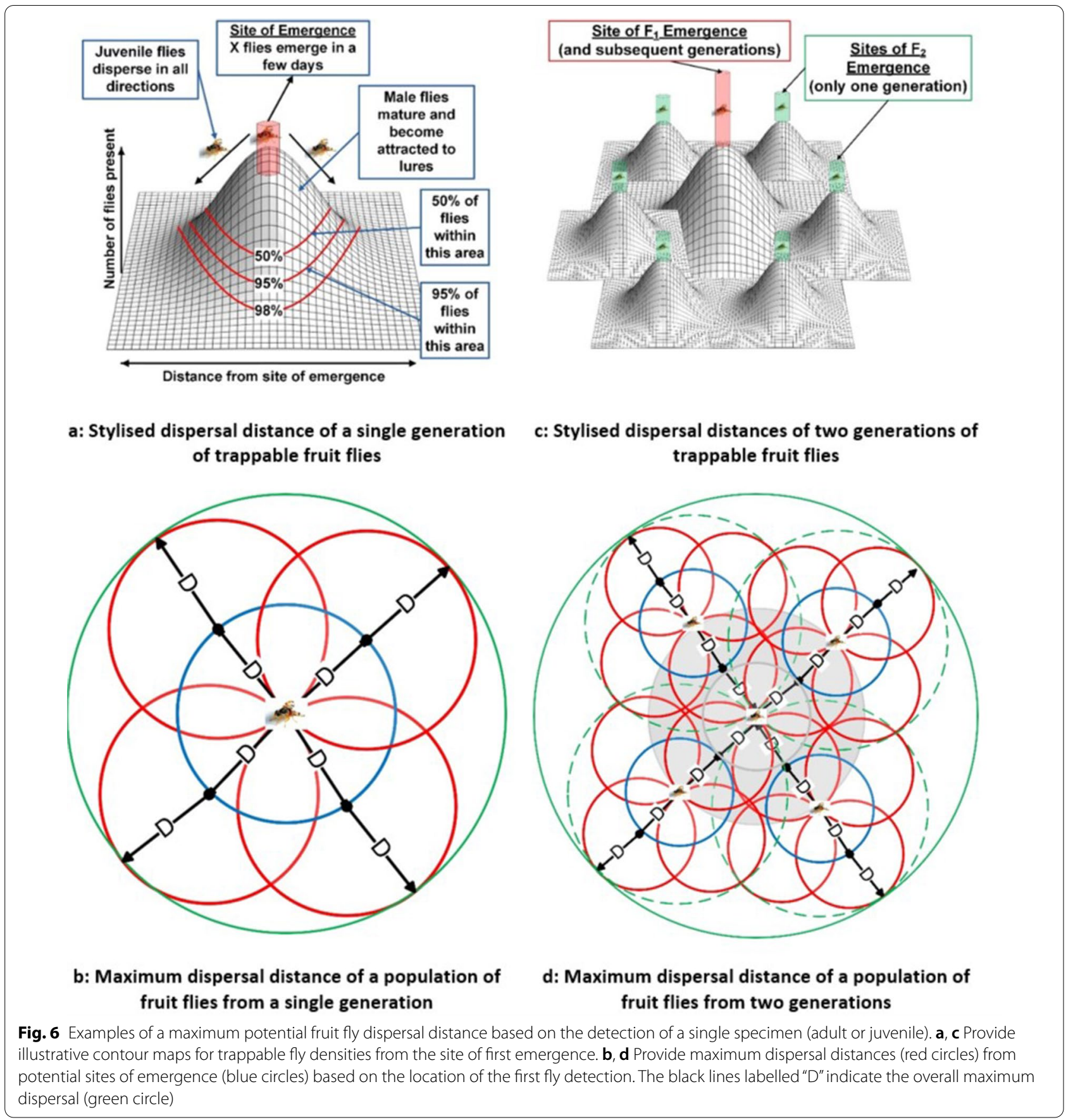

dispersal distance (the blue circle) from the point the fly was trapped. If (in a worst case scenario) the fly had flown the maximum dispersal distance (e.g. the population epicentre on the outer line of the blue circle), the population of first generation of emergent flies could have dispersed anywhere within the red circle (four red circles are drawn here as examples). The green circle encases all the possible areas the population of flies could exist based on the detection of the single fly. The green circle with a radius of twice the maximum dispersal distance therefore represents a worst-case scenario for possible fruit fly population distribution when only a single generation $\left(\mathrm{F}_{1}\right)$ of fruit flies have emerged. Maximum dispersal distance can only be achieved if the fly flies in a straight line with minimum death rate; flies usually have a more random series of flights, so the 
maximum dispersal distance is already overly optimistic (Dominiak pers. comm.).

If detection of a population of fruit flies is sufficiently delayed to potentially allow two generations $\left(\mathrm{F}_{2}\right)$ of flies to emerge (Fig. 6c), the relationship between the maximum dispersal distance and the ERZ can be demonstrated by the diagram provided by Fig. $6 \mathrm{~d}$. The green circle encases all the possible areas the population of flies could exist based on the detection of the single fly. The green circle with a radius of four times the maximum dispersal distance (twice the radius of a single generation) therefore represents a worst-case scenario for possible fruit fly population distribution when two generations $\left(\mathrm{F}_{2}\right)$ of fruit flies have emerged.

The question then becomes: How do we know if the surveillance system is likely to detect a population in or before the first $\left(\mathrm{F}_{1}\right)$ or second $\left(\mathrm{F}_{2}\right)$ generations?

This could be answered using the calculations which determine the potential size of the population present when a detection is made by the surveillance system. If the potential size of the population detected by the surveillance system is greater than the population size needed to enable a breeding pair to successfully establish a new population, then the confidence is lower that a second generation of flies has not arisen. For example: when the breeding population size is 50 flies but the surveillance system is most likely to only detect a population of 85 individuals or more, then there is the potential for a breeding pair from the first generation to have established a second generation $(85>50)$.

The sensitivity of the surveillance trapping system to detect a fruit fly population can be calculated using Eq. 4.

Equation 4: Calculating the sensitivity of a fruit fly surveillance system in detecting a fruit fly population.

$$
S=1-\exp \left(-E S A_{\text {med }} \times T_{d} \times N_{t}\right)
$$

where $S=$ the sensitivity of the fruit fly trapping grid measured as the probability of detecting one or more male flies given a population of $N_{t}$ adult males of a particular fruit fly species. $E S A_{\text {med }}=$ the median effective sampling area (ha) of each trap in the trapping grid for a fruit fly species. $T_{d}=$ the trap density of the surveillance grid (traps per hectare). $N_{t}=$ the total number of detectable (male) flies assumed to be in the area.

When a detection occurs in a surveillance trap, the greatest likely number of adult male fruit flies of a particular species in the area $\left(N_{t}\right)$ can be estimated for each fruit fly species as the number present when the probability of detecting one male fly $(S)$ exceeds $95 \%$. Then, the size of the $E R Z$ can be estimated based on this value of $N_{t}$ and the known distribution pattern of the fruit fly population $\left(\boldsymbol{P}_{\boldsymbol{r}}\right)$ (see Eq. 5).
Equation 5: Calculating the number of flies outside an area with a specified radius for a fruit fly population of known size and pattern of distribution.

$$
N_{r}=N_{t}-\left(N_{t} \times P_{r}\right)
$$

where $N_{r}=$ the number of male flies likely to be outside of the area with a radius of $r . N_{t}=$ the total number of detectable (male) flies assumed to be in the area. $P_{r}=$ the cumulative percentage of flies found within the area that has a radius of $r$. This parameter is based on the adult fly distribution curves calculated for each fly species.

The value of $N_{r}$ can be estimated for areas with an increasing radius. Therefore, the radius of the ERZ is two or more times the radius required to ensure the number of male flies outside of the area $\left(N_{r}\right)$ is less than one i.e. zero male flies (see Fig. 6).

\section{Determining when to Remove an Export Restriction Zone}

The current practice for determining when to end an eradication programme (and remove an ERZ) specifies a time interval during which no further fruit fly detections are recorded, and should be based on the biology of the fruit fly and prevailing environmental conditions (FAO 2016). Meats and Clift (2005) noted that these time intervals have used a physiological time scale (day-degrees) which was equivalent to one generation plus 28 days (e.g. Australia) or up to three generations (e.g. USA) or more and can only usually be determined at the time of the response (see Kean (2015b) for a meta-analysis of fruit fly development times). Meats and Clift (2005) proposed an alternative method which used a pre-determined time interval, based on measured trap sensitivity and trapping density, and does not require the calculation of generation length under different temperature scenarios. The authors further suggest that time periods during which temperatures fall below adult maturation (life-cycle development) and/or effective movement thresholds (and therefore adult attraction to trap lures) should not be included when calculating the length of zero trapping.

I propose that one criterion for the time interval to remove the ERZ be based on trapping sensitivity, and is achieved when the probability that the area is free of a population of the target fruit fly species is equal to or greater than a $95 \%$ level of confidence. Additionally, I propose that a minimum time equivalent to one generation (egg to mature (trap sensitive) adult fly) and 4 weeks (a single trapping period) under existing climatic conditions and under a continuous (uninterrupted) trapping period should be required to ensure that if any immature fruit flies are present they will be detected. A similar approach for declaring areas free of insects has been proposed previously by Barclay and Hargrove (2005) where trapping periods are interrupted by a suitably long 
winter, and the fruit fly species in question over-winters in the adult life stage. Therefore, the minimum requirement of a single generation may not be necessary as no juvenile life stages will be present when climatic conditions become suitable for trapping once more.

This level of confidence in fruit fly freedom can be achieved via two main routes:

a. For non-persistent populations, the onset of cold weather seasons will remove the population and ensure the next production season is free of that fruit fly species;

b. A sufficient period of zero fruit fly detections (of any life stage) providing at least a $95 \%$ level of confidence that the area within the $E R Z$ is free of the fruit fly in question.

For the first situation (a), the information required to determine if a fruit fly is only able to form a seasonal population in an area is determined by the climate of that region (winter temperatures and duration).

For the second situation (b), the probability that an area does not have an established population for each period of zero trapped flies can be calculated using Eq. 6 .

Equation 6: Calculating the sensitivity of a fruit fly surveillance system in detecting one or more flies in a population over multiple periods.

$$
P_{n}=1-\exp \left(-N \times E S A_{\text {med }} \times T_{d}\right)^{a}
$$

where $P_{n}=$ The probability of detecting $n$ trappable insects that arise within the trapping area over $a$ trapping periods. $E S A_{\text {med }}=$ The median effective sampling area (ha) of each trap in the trapping grid for a fruit fly species. $N=$ The threshold number of trappable insects arising independently within the surveillance area, which in this instance would be the minimum number required to establish a population. $T_{d}=$ The trapping density of the trapping area for each fruit fly species (traps per hectare) during the eradication phase of the response. $a=$ The number of trapping periods.

In these calculations each trapping period is equivalent to the length of time taken to lure the adult males used in the experiments to determine the level of trap sensitivity, and only applies to periods when the environmental conditions (e.g. temperature) are sufficient to support adult fly attraction to lures (e.g. sufficient maturation and/or effective flight). For the purposes of this analysis, I assumed that the minimum possible number of adult male fruit flies required to establish a population in a new area is 2 (or more). This is a very conservative number and is different from the breeding population size which provides a more realistic estimate of the number of flies required to establish a population.

\section{Fruit fly data for models}

For the purposes of demonstrating the use of these models, I collated relevant data on two of economically important tephritid fruit fly species: Queensland fruit fly (B. tryoni) and Oriental fruit fly (B. dorsalis).

In all tephritid fruit fly species, the adult is the only stage capable of dispersal independently of its host (or vector in the case of pupae). Eggs are laid below the skin of the host fruit. Generally, these hatch within 1-3 days, and the larvae feed for 10-31 days (Garcia 2009). Ripe fruit falls to the ground, or larvae leave the hanging fruit and drop to the ground and pupation is in the soil under the host plant (Bateman 1972). The lure-based traps used in the fruit fly surveillance systems almost exclusively attract only mature (sexually active) male flies (Royer 2015).

\section{Data for Queensland fruit fly}

Queensland fruit fly (B. tryoni) is very destructive to a wide range of fruit hosts and is the most costly and serious insect pest of horticulture in Australia (Dominiak et al. 2015; Dominiak and Mapson 2017).

Adult fly dispersal behaviour is influenced by many factors, including availability of food (primarily sugars and protein), temperature, humidity, wind, odours, life span, escaping predators, and fruit suitable for oviposition (Yonow et al. 2004; Clarke et al. 2011). Additionally, dispersal is influenced by sexual status, though not necessarily sex (Weldon 2005). Sexually immature (post-teneral) adult $B$. tryoni males tend to disperse away from the site of pupal emergence, regardless of the suitability of the immediate habitat for survival and reproduction (Weldon 2005). Movement by sexually mature adult $B$. tryoni is typically non-dispersive, involving local movements to search for food, mates and oviposition sites. However dispersive movement has been reported in sexually mature adult $B$. tryon $i$ in response to adversity, including lack of adequate oviposition sites (Weldon 2005).

Most studies have concluded that the lifetime dispersal distance of $B$. tryoni rarely exceeds $600 \mathrm{~m}$ (Dominiak 2012; Dominiak and Fanson 2020), although two studies indicate that longer dispersal distances of a small number of individuals may occasionally occur: Fletcher (1974) claimed that B. tryoni could disperse up to $22.7 \mathrm{~km}$, and MacFarlane et al. (1987) reported a single B. tryoni was found $94 \mathrm{~km}$ from the release point. Weldon (2005), in release/recapture experiments in New South Wales, Australia, found that recaptures of most male and female $B$. tryoni were made within $500 \mathrm{~m}$ of the release point, although a small proportion of males were found over $1000 \mathrm{~m}$ from the release point two weeks after release. Weldon 


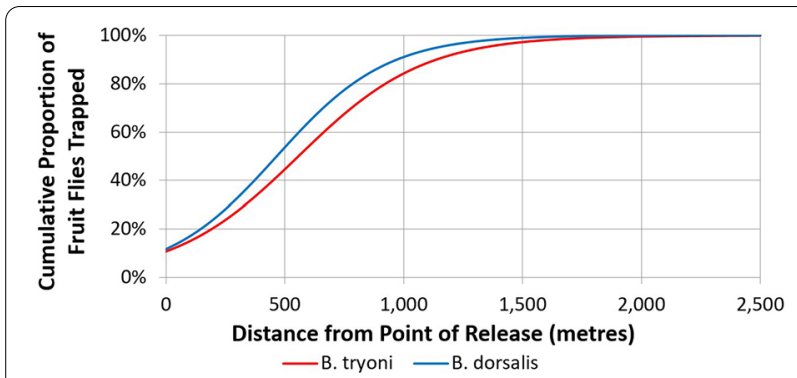

Fig. 7 The cumulative dispersal distance of B. tryoni and B. dorsalis adults from a single point of release or emergence

(2005) also found that laboratory-rearing and sterilisation did not significantly affect dispersal ability of post-teneral male $B$. tryoni relative to wild flies. Meats and Edgerton (2008) indicated that these longdistance dispersals became over dispersed and did not participate in matings. I therefore consider that these over-dispersed flies do not contribute to ERZ calculations, recognising that equivalent studies on gravid female fly dispersal distances are not available. These short dispersal distances are consistent with findings for other fruit fly species (Dominiak 2012; Dominiak and Fanson 2020). Long-distance dispersal has been linked to isolated favourable habitats separated by resource poor country that forced dispersing flies to make longer flights. In favourable habitats, such as large urban areas or well-managed orchards, dispersal distances are likely to be relatively short (Raghu et al. 2000; Dominiak 2012; Dominiak and Fanson 2020).

Dominiak et al. (2013) reviewed historical release and capture data from a programme of work in New South Wales Australia in 1998/99. Of the 19,758 sterile flies released over the summer months, $95 \%$ of those trapped were within $1360 \mathrm{~m}$ of their point of release, $98 \%$ within $1574 \mathrm{~m}$, and $100 \%$ within $5553 \mathrm{~m}$. The authors estimated that $99.9 \%$ of the released flies that were caught were within $2159 \mathrm{~m}$ of the point of release. From distribution data provided by the review of Dominiak et al. (2013), an adult fly distribution model was developed for $B$. tryoni using a generalised linear model with a binomial error distribution which accounts for over-dispersion. The predicted distribution curve developed from this model is shown in Fig. 7.

Based on Fig. 7, I estimate that after two to three weeks of emergence (once the male flies mature and become attracted to the trapping lures), $95 \%$ of the emergent flies can be found within a radius of $1340 \mathrm{~m}$ of the point of release and $99 \%$ of the flies can be found within a radius of $1770 \mathrm{~m}$.

\section{Data for Oriental Fruit Fly}

Oriental Fruit Fly (B. dorsalis) forms part of a species complex, within which over 50 species have been described in Asia (EPPO 2009). Schutze et al. (2015) recently synonymised Bactrocera papayae Drew \& Hancock and Bactrocera invadens Drew, Tsuruta \& White with $B$. dorsalis sensu stricto. Prior to this Drew and Romig (2013) synonymised Bactrocera philippinensis Drew \& Hancock with B. papaya. The data included in this paper pre-dated the synonymizing and as such is $B$. dorsalis sensu stricto only (as at 2014).

The $B$. dorsalis adult is a strong flyer, recorded to travel up to $50 \mathrm{~km}$ in search of food and sites to lay eggs. In studies on foraging behaviour, adult flies of $B$. dorsalis was recorded moving up to $600 \mathrm{~m}$ between areas of food and non-food plants in field experiments in Taiwan (Chiu 1983), where observations found that bamboo stands were the most preferred sites for resting. The transport of infested fruits is the main means of global movement and dispersal to previously uninfested areas (EPPO 2009).

Froerer et al. (2010) studied the long-distance dispersal of $B$. dorsalis in Hawaii:

- Unassisted long-distance flights of between 2 and $11.39 \mathrm{~km}$ were reliably recorded, but these were very rare events. A total of 217,560 adult flies were released in 4 releases, of which only 30 (0.000137\%) were recovered at distances over $2 \mathrm{~km}$.

- Only one of the four releases looked at median distance dispersal: 90,078 flies were released and a total of 1,887 flies were recovered from the fourth release at distances ranging from 0.02 to $1.90 \mathrm{~km}$.

- While short-distance movement occurred for over 2 weeks, long-distance movement seems to have occurred within a short period of time after a release.

Using a generalised linear model with a binomial error distribution which accounts for over-dispersion, the predicted distribution curves for $B$. dorsalis are shown in Fig. 7.

\section{Country data for models New Zealand and B. tryoni/B. dorsalis}

The base-line level of assurance supporting New Zealand's fruit fly free status is provided by the New Zealand's fruit fly surveillance programme. Approximately 7,500 lure traps (Lynfield design) are set up and maintained from September to June of each year (Quilici and Donner 2012; Acosta and White 2011). Traps are placed in arrays, concentrating in populated areas serving as centres for tourism and/or trade, areas of significant horticultural activity, and areas climatically conducive to the 
establishment of fruit flies (MPI 2014). The density of traps in the arrays reflects to a degree the effective trapping distances of each trapping lure. A summary of the details on New Zealand's surveillance and response system (MPI 2014) are provided in Table 2.

\section{Australia and B. tryoni}

The surveillance system for B. tryoni was established by each of the states of Australia under the Fruit Fly Code of Practice (COP 2014). In areas where freedom from $B$. tryoni is being maintained, male cure-lure baited Steiner or Lynfield traps are placed in $1000 \mathrm{~m}$ grids within commercial host growing areas (e.g. orchards) and in 400-m grids in urban areas (COP 2014).

Additionally, the federal standard for response to $B$. tryoni in Australia are contained in COP (2014). As B. tryoni is now considered endemic to coastal areas of Queensland, New South Wales and Victoria, Australia, COP (2014) for this fruit fly applies to areas outside of this distribution range. For a $B$. tryoni response COP (2014) requires the use of cue-lure based surveillance. A summary of the details on Australia's surveillance and response system (COP 2014) are provided in Table 2.

\section{USA (California) and B. dorsalis}

Little detail could be found on the Californian surveillance system for $B$. dorsalis, for the purposes of this paper, I assumed that it meets the minimum requirements for maintaining a PFA as detailed in RSPM 17 (2010). This standard requires for methyl eugenol-responsive species (e.g. B. dorsalis) that the trap density in high risk areas (entry points etc.) is three traps per $\mathrm{km}^{2}$, urban areas is one trap per $\mathrm{km}^{2}$ (1000 $\mathrm{m}$ trapping grid), and in commercial production areas is two traps per $2 \mathrm{~km}^{2}(2000 \mathrm{~m}$ trapping grid). The State of California's response to $B$. dorsalis occurs under the guidelines provided in the USDA APHIS Action Plan for Oriental Fruit Fly (USDA APHIS 1989).

For the purposes of this paper, I assume that after the date of the last fruit fly detection surveillance for fruit flies will return to the trapping system described above for the delimitation area (the $1000 \mathrm{~m}$ trapping grid with a further 400 traps out to a $8.2 \mathrm{~km}$ radius in urban areas and the $2000 \mathrm{~m}$ trapping grid with a further 400 traps out to a $8.2 \mathrm{~km}$ radius in commercial production areas). A summary of the details on California's surveillance and response system (USDA APHIS 1989) are provided in Table 2.

\section{Simplification of surveillance and response scenarios used in this analysis}

Each surveillance system provides a level of sensitivity in its ability to detect a fruit fly population based on the nature of the lures and traps used and the density of the trapping grid. The minimum number of traps deployed in each surveillance area has been simplified for each fruit fly species within each country to determine the trigger numbers, size of an ERZ, and the criteria for removing an ERZ. Detection sensitivities across surveillance areas can only be modelled when the distribution of the targeted fruit fly is known with some accuracy. In most eradication scenarios the distribution of the fruit fly only becomes apparent part way through the eradication campaign. To avoid situations where trapping densities vary across a surveillance or eradication areas, each of the surveillance and response scenarios considered in this analysis was simplified (using conservative (worst-case) trapping densities by understating the number of traps in each area) as detailed in Table 2.

\section{Results}

Calculations for response criteria for Queensland Fruit Fly (B. tryoni)

Population size required for establishment

Meats (1998b) calculated that for B. tryoni the founder population size to successfully establish was 12 flies per hectare containing host material. As the sex ratio in $B$. tryoni is 1:1 (Clarke and Dominiak 2012; Fanson et al. 2014), a population of 12 adult flies is most likely to contain 6 male flies. As the highest population concentration of $B$. tryoni male flies in any single outbreak scenario is at its centre, from the distribution data shown in Fig. 7 we can determine the total trappable population size required to achieve or exceed 12 adult flies ( 6 male flies) in the centre 1 hectare of the population.

From the distribution model shown in Fig. 7, we can determine that the proportion of the total fruit fly population present in the centre $60 \mathrm{~m}$ radius $(\mathrm{r})$, which for $\mathrm{B}$. tryoni is $13.2 \%$. By increasing the number of flies emerging we can determine the threshold for achieving more than 6 male flies in that centre $60 \mathrm{~m}$ circle using Eq. 2 .

The results derived from this Eq. 2 applied to the data for B. tryoni are provided in Fig. 8.

From Fig. 8, I found that a population of 52 adult male flies (104 adult flies) or more may result in a density of flies at the centre of the outbreak that exceeds the founder population size ( 6 male flies) as determined by Meats (1998b). Therefore, I assume the breeding population size for B. tryoni was 52 male files or 104 male or female adult flies (given the sex ratio in B. tryoni is 1:1 (Meats 1998b)).

Trigger for imposing an export restriction zone for $B$. tryoni From the response parameters and the biological description of $B$. tryoni, the variables required to determine the probability of detecting male flies using a trapping grid 


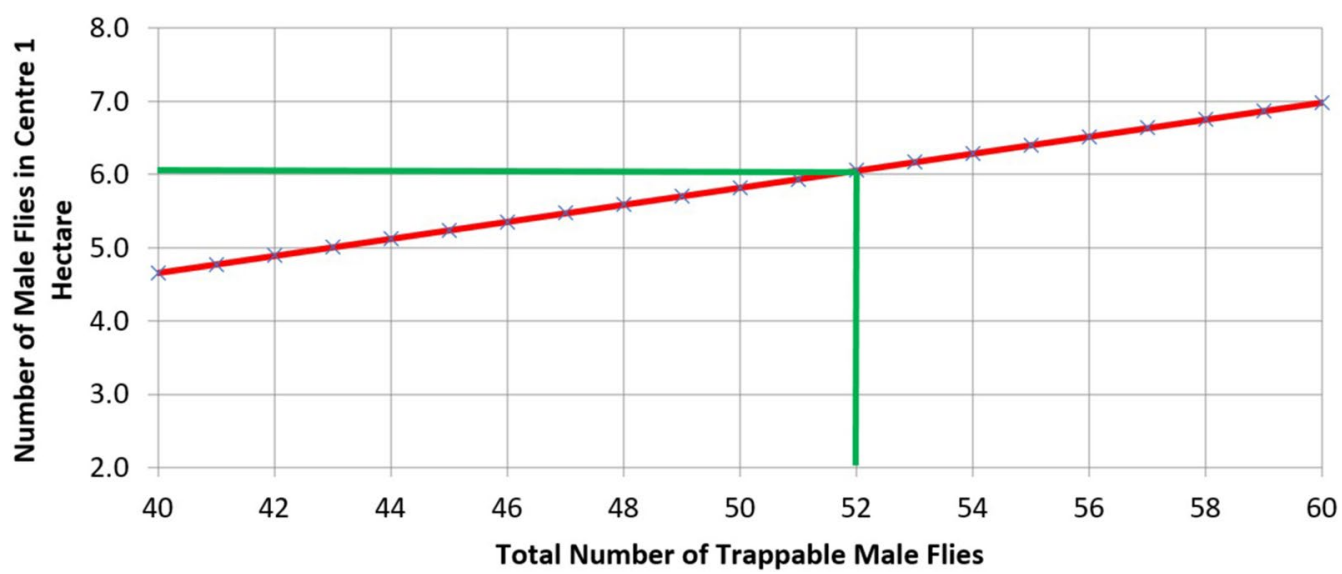

Fig. 8 Determining the population of adult B. tryoni males in a region required to exceed the founder population density in the centre 1 hectare of the outbreak. Red line is the estimated total number of male files present ( $x$ axis) with a given number of male flies in the centre 1 hectare. Green lines indicate the founder population density given a founder population size of 6 male flies

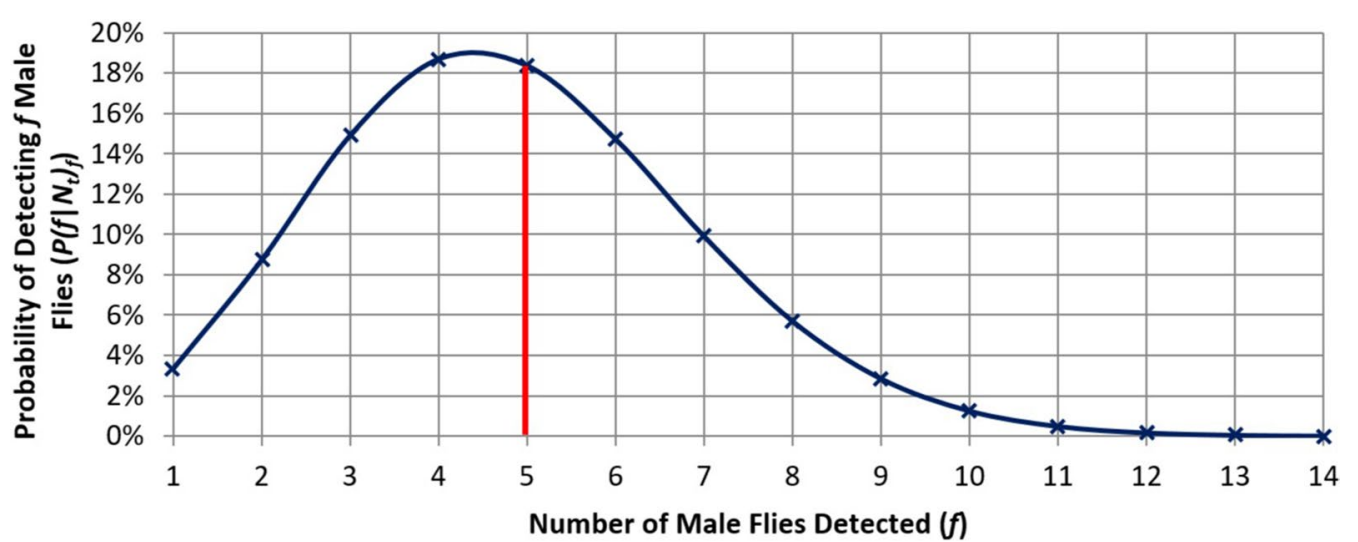

Fig. 9 The probability of detecting $f$ male flies from a total population of 52 adult $B$. tryoni males using a $400 \mathrm{~m}$ trapping grid over the life of the traps

during intelligence gathering activities (surveillance) for Australia and New Zealand and are as follows:

- The number of detectable (male) flies in the area estimated to be required to establish a breeding population $\left(N_{t}\right)$ of $B$. tryoni is 52 (the breeding population size).

- For New Zealand and urban areas in Australia, the minimum trap density $\left(T_{d}\right)$ in the delimitation zone for $B$. tryoni is 0.065 traps per hectare.

- For production areas in Australia, the minimum trap density $\left(T_{d}\right)$ in the delimitation zone for $B$. tryoni is 0.0104 traps per hectare.

- A median estimate of the effective sampling area $\left(E S A_{\text {med }}\right)$ of each trap in a trapping grid for B. tryoni using the cue-lure bait is 1.5 ha.
- For New Zealand and urban areas in Australia, the probability $(p)$ of trapping a single male $B$. tryoni in the delimitation area can be calculated from the $E S A_{\text {med }}$ and trap density $\left(T_{d}\right)$ as $1-\exp \left(-E S A_{\text {med }} \times T_{d}\right)$, which equates to 0.0929 .

- For production areas in Australia, the probability $(p)$ of trapping a single male $B$. tryoni in the delimitation zone can be calculated from the $E S A_{\text {med }}$ and trap density $\left(T_{d}\right)$ above as $1-\exp \left(-E S A_{\text {med }} \times T_{d}\right)$, which equates to 0.02 .

Using Eq. 3, the probability $\left(P\left(f \mid N_{t}\right)_{f}\right)$ of detecting $f$ flies in New Zealand and urban areas in Australia can be determined for a range of values of $f$ and the trigger number determined by observing when the results achieve the highest level of detection (see Fig. 9). 


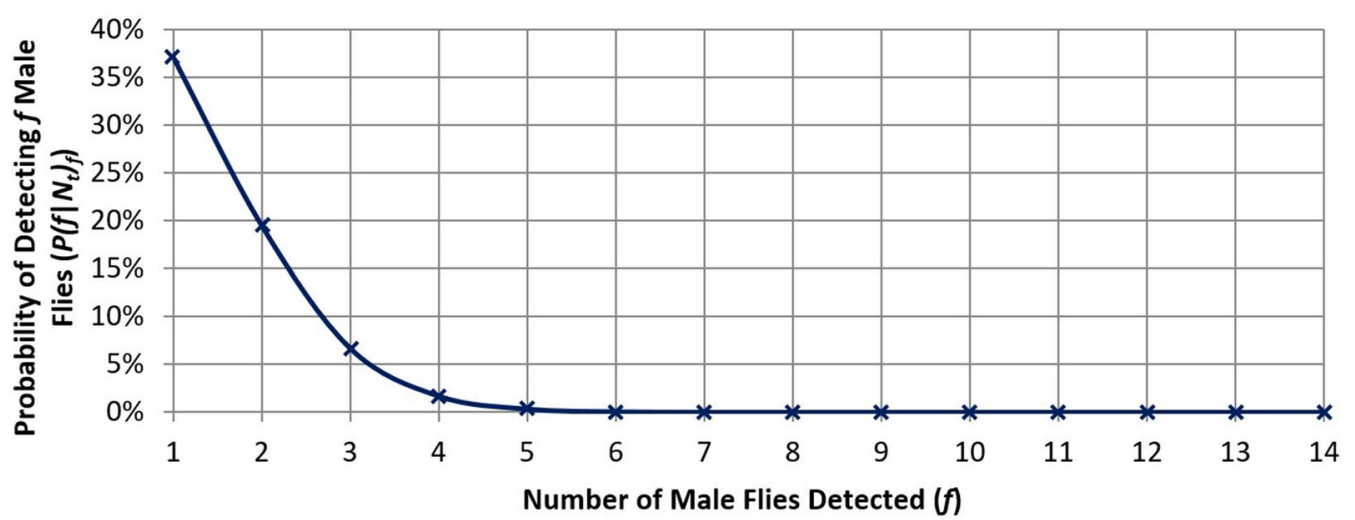

Fig. 10 The probability of detecting $f$ male flies from a total population of 52 adult B. tryoni males using a 1000-m trapping grid over the life of the traps

Measurements that were taken to determine the level of trap sensitivity were based on laboratory-reared sterile (non-fertile) flies that were captured over a 4-week period after release (Dominiak et al. 2013). This is less than the estimated 7 weeks required for a population to be reduced to $50 \%$ of its original level, although $B$. tryoni male adults require around two weeks to mature (to become attracted to trap lures) (Meats 1998b), leaving around 4 to 5 weeks of trapping mature lure-attracted male flies.

From Fig. 9, I found that the detection of 5 male $B$. tryoni in a 4-week period would suggest that it is more likely than not that the maximum acceptable population size is exceeded. This provides a fly trigger level of 5 adult flies within 4 weeks (28 days) for New Zealand and urban areas in Australia. For the two-week trigger period, around half the flies are required for half the length of time, ${ }^{1}$ which equates to 3 adult $B$. tryoni males within 2 weeks (14 days) providing an equivalent trigger for establishing an ERZ.

For production areas in Australia, where the trapping density is only 0.0136 traps per hectare and the probability of trapping a single male $B$. tryoni is 0.02 ; the detection probability is so low (see Fig. 10) that detecting any male flies would indicate the maximum acceptable population size has been exceeded.

\section{Calculating the size of an export restriction zone for $B$. tryoni}

From the response parameters and the biological description of B. tryoni provided, the variables required to determine the sensitivity of the surveillance trapping system used in New Zealand and Australia to detect B. tryoni populations are as follows:

- A median estimate of the effective sampling area $\left(E S A_{\text {med }}\right)$ of each trap in a trapping grid for B. tryoni using the cue-lure bait is 1.5 ha.

- In New Zealand and in urban areas of Australia they use a $400 \mathrm{~m}$ surveillance grid to detect B. tryoni, which provides a trap density $\left(\boldsymbol{T}_{\boldsymbol{d}}\right)$ of 0.065 traps per hectare.

- In production areas in Australia they use a 1000 m surveillance grid to detect B. tryoni, which provides a trap density $\left(\boldsymbol{T}_{\boldsymbol{d}}\right)$ of 0.0104 traps per hectare.

The calculations from applying Eq. 4 predict that the 400-m surveillance grids used in New Zealand and urban areas of Australia have at least a 95\% probability of detecting one fly in a population of 31 or more male $B$. tryoni flies in an area. The same calculations predict that the 1000-m surveillance grid used in production areas of Australia has at least a $95 \%$ probability of detecting one fly in a population of 192 or more male B. tryoni flies in an area.

The population size likely to be detected by the 400-m surveillance grids in New Zealand and urban areas of Australia (31) is less than the breeding population size for B. tryoni of 52, indicating only one generation of flies is likely to be present. However, the population size likely to be detected by the 1000-m surveillance grids in urban areas of Australia (192) is considerably more than the breeding population size for $B$. tryoni of 52, indicating more than one generation of flies may be present.

Therefore, to determine the size of the ERZ for B. tryoni detected using a $400-\mathrm{m}$ surveillance grid it is proposed that, before an $E R Z$ is established: 
a) The population size likely to be in the area would be the breeding population size: namely 52 adult male flies; and

b) The trigger number of 3 flies would need to be captured over 14 days; and

c) Only one generation $\left(F_{1}\right)$ of flies may have emerged in the area.

Using Eq. 5, values for the number of male flies outside a trapping area $\left(N_{r}\right)$ can be calculated over a range of increasing distances from the population epicentre $\left(\boldsymbol{P}_{\boldsymbol{r}}\right)$. The results suggest that under a $400-\mathrm{m}$ trapping grid there are unlikely to be any male flies (or gravid female files or both) more than $1600 \mathrm{~m}$ from the epicentre. The radius of the ERZ for only one generation $\left(\mathrm{F}_{1}\right)$ of $B$. tryoni would then equal twice this radius (see Fig. $6 \mathrm{~b})$ or $3200 \mathrm{~m}$.

To determine the size of the $E R Z$ for $B$. tryoni detected using a $1000-\mathrm{m}$ surveillance grid it is proposed that, before an $E R Z$ is established:

a) The population size likely to be in the area would be 192 adult male flies; and

b) The trigger number of 1 fly would need to be captured over 14 days; and

c) Two generations $\left(\mathrm{F}_{2}\right)$ of flies may have emerged in the area (e.g. 192>52).

Using Eq. 5 above, values for the number of male flies outside a trapping area $\left(N_{r}\right)$ can be calculated over a range of increasing distances from the population epicentre $\left(P_{r}\right)$. The results suggest there are unlikely to be any male flies more than $1950 \mathrm{~m}$ from the epicentre. The radius of the ERZ for two generations $\left(\mathrm{F}_{2}\right)$ of $B$. tryoni would then equal four times this radius (see Fig. 6d) or $7,800 \mathrm{~m}$.

Criteria for removing an export restriction zone for $B$. tryoni From the response parameters and the biological description of $B$. tryoni provided above, the variables required to determine the length of trapping period required to provide a $95 \%$ level of confidence that the ERZ can be removed from New Zealand and Australia are as follows:

- New Zealand applies a surveillance trap density (Td) of 0.283 traps per hectare to detect B. tryoni after the last fruit fly has been detected.

- Australia uses a 400-m surveillance grid to detect B. tryoni after the last fruit fly has been detected, which provides a trap density (Td) of 0.065 traps per hectare.
- A median estimate of the effective sampling area $\left(\boldsymbol{E S} \boldsymbol{A}_{\text {med }}\right)$ of each trap in a trapping grid for B. tryoni using the cue-lure bait is 1.5 ha.

By plotting the cumulative probabilities of detecting two male flies in a trap density $\left(\boldsymbol{T}_{\boldsymbol{d}}\right)$ of 0.283 traps per hectare (New Zealand scenario) over more than one trapping period (4 weeks) using Eq. 6, I found that 3.5 trapping periods or just under 14 weeks of no fly detections would provide $>95 \%$ probability that a breeding fly population ( $>2$ male flies) no longer exists in the area.

Doing the same under the Australian scenario of detecting two male flies in a trap density $\left(\boldsymbol{T}_{d}\right)$ of 0.065 traps per hectare over more than one trapping period (4 weeks), I found that 15.4 trapping periods or just under 61.6 weeks of zero fly detections would provide $>95 \%$ probability that a breeding fly population ( $>2$ male flies) no longer exists in the area covered by 0.065 traps per hectare.

\section{Calculations for response criteria for $\boldsymbol{B}$. dorsalis} Population size required to enable establishment

Meats (1998a, b) calculated that for B. tryoni the 'founder population size' was 12 flies per hectare. To do this, Meats (1998a, b) had to determine several biological characteristics for B. tryoni that would also need to be found for $B$. dorsalis to complete the same assessment. I could find no equivalent analysis for $B$. dorsalis in the literature. Baker et al. (1990) noted that three sexually mature adult flies were required to have any likelihood of a population establishing in an area. As the sex ratio in B. dorsalis is 1:1 (Binay and Agarwal 2005), a population of $>3$ adult flies was most likely to contain $>1$ male fly. For the purposes of this analysis, I will conservatively assume that the number of emerging adult flies required to establish a population in a new area contains 2 (or more) male flies.

As the highest population concentration of $B$. dorsalis male flies in any single outbreak scenario is at its centre, and using the distribution data shown in Fig. 7, we can determine the total emergent population size required to achieve or exceed $>3$ adult flies ( 2 male flies) in the centre 1 hectare of the population. A circle with a radius of $60 \mathrm{~m}$ is just over 1 hectare (1.13 ha) in area. From the distribution model shown in Fig. 7, we can determine that the proportion of the total fruit fly population present in the centre $60 \mathrm{~m}$ radius (r), which for $B$. dorsalis is $11.7 \%$. We can determine the threshold for achieving more than 2 male flies in that centre $60 \mathrm{~m}$ circle using Eq. 2 by increasing the number of invading or emerging flies.

We can calculate values for the threshold number of detectable flies in the area over a range of increasing populations of invading or emerging flies $\left(N_{t}\right)$ when the density of flies in the centre $60 \mathrm{~m}$ radius circle $\left(D_{r}\right)$ exceeds 2 
male files. I found that a population of 16 adult male flies (32 adult flies) or more may result in a density of flies at the centre of the outbreak that exceeds the founder population size ( 2 male flies or 3 flies in total). I will therefore assume the establishment population size for $B$. dorsalis is 16 male files or 32 adult flies (given the sex ratio in $B$. dorsalis is 1:1 (Binay and Agarwal 2005)).

\section{Trigger for B. dorsalis Export Restriction Zone}

Using the response parameters and the biological description of $B$. dorsalis, I found that the variables required to determine the probability of detecting male flies using a trapping grid during surveillance for California, USA, and New Zealand were as follows:

- The number of detectable (male) flies in the area estimated to be required to establish a breeding population $\left(N_{t}\right)$ of $B$. dorsalis is 16 (the breeding population size).

- For New Zealand, the minimum trap density $\left(T_{d}\right)$ in the delimitation zone for $B$. dorsalis is 0.0077 traps per hectare.

- For urban areas in California, the minimum trap density $\left(T_{d}\right)$ in the delimitation zone for $B$. dorsalis is 0.0104 traps per hectare.

- For production areas in California, the minimum trap density $\left(T_{d}\right)$ in the delimitation zone for $B$. dorsalis is 0.0026 traps per hectare.

- A median estimate of the effective sampling area ( $E S A_{\text {med }}$ ) of each trap in a trapping grid for B. dorsalis using the methyl eugenol bait is 9 ha.

- For New Zealand, the probability $(p)$ trapping a single male $B$. dorsalis in the New Zealand surveillance grid can be calculated from the $E S A_{\text {med }}$ and trap density $\left(T_{d}\right)$ above as $1-\exp \left(-E S A_{\text {med }} \times T_{d}\right)$, which equates to 0.0667 .

- For urban areas in California, the probability $(p)$ of trapping a single male $B$. dorsalis in the delimitation zone can be calculated from the $E S A_{\text {med }}$ and trap density $\left(T_{d}\right)$ above as $1-\exp \left(-E S A_{\text {med }} \times T_{d}\right)$, which equates to 0.0894 .

- For production areas in California, the probability $(p)$ of trapping a single male $B$. dorsalis in the delimitation zone can be calculated from the $E S A_{\text {med }}$ and trap density $\left(T_{d}\right)$ above as $1-\exp \left(-E S A_{\text {med }} \times T_{d}\right)$, which equates to 0.023 .

Using Eq. 3, the probability $\left(P\left(f \mid N_{t}\right)_{f}\right)$ of detecting $\boldsymbol{f}$ flies in New Zealand and California can be determined for a range of values of $\boldsymbol{f}$ and the trigger number determined by observing when the results achieve the highest level of detection. The results were calculated for urban areas in
California as this is the most sensitive surveillance system of the three examples.

Vargas and Carey (1990) and Vargas et al. (2000) observed laboratory-reared flies in environmental chambers and found that $B$. dorsalis adults survived for around 50 to 200 days depending on temperatures. Bactrocera dorsalis male adults require around two to four weeks to mature (to become attracted to trap lures) (Vargas pers. com.) leaving 7 to 9 weeks of effective trapping before adult population numbers declined beyond $50 \%$. Measurements that were taken to determine the level of trap sensitivity (ESA) were based on flies that were captured up to 4 weeks after release (Froerer et al. 2010) which is less than the estimated time taken for the population to decline to $50 \%$.

From the results I concluded that the detection of 1 male $B$. dorsalis in a $1000-\mathrm{m}$ surveillance grid would suggest that it is more likely than not that the maximum acceptable population size is exceeded. As the New Zealand surveillance grid $(1200 \mathrm{~m})$ and the surveillance grid in production areas in California $(2000 \mathrm{~m})$ are less sensitive than the urban surveillance grid $(1000 \mathrm{~m})$, I consider that they would have a single-fly trigger.

\section{Calculating the size of an export restriction zone for $B$. dorsalis}

From the response parameters and biological description of $B$. dorsalis provided earlier, the variables required to determine the sensitivity of the surveillance trapping system used in New Zealand and California, USA, to detect B. dorsalis populations are as follows:

- New Zealand uses a 1,200-m surveillance grid to detect $B$. dorsalis which provides a trap density $(\mathrm{Td})$ of 0.0072 traps per hectare.

- For urban areas in California, the minimum trap density (Td) in the delimitation zone for B. dorsalis is 0.0104 traps per hectare.

- For production areas in California, the minimum trap density $(\mathrm{Td})$ in the delimitation zone for $B$. dorsalis is 0.0026 traps per hectare.

- A median estimate of the effective sampling area ( $\boldsymbol{E S} \boldsymbol{A}_{\text {med }}$ ) of each trap in a trapping grid for B. dorsalis using the methyl eugenol bait is 9 ha.

From the results obtained from applying Eq. 4 to calculate trapping sensitivity $(S)$ for New Zealand (1200-m surveillance grid) over a range of adult male population sizes $\left(N_{t}\right)$ I estimate that the current surveillance grid used in New Zealand to detect $B$. dorsalis populations has at least a $95 \%$ probability of detecting one fly in a population of 47 or more male flies in an area. Repeating the same calculations for urban (1000 m grid) and 
Table 3 Summary of results from calculations for New Zealand, Australia and California control scenarios for B. tryoni and B. dorsalis

\begin{tabular}{|c|c|c|c|c|}
\hline \multicolumn{2}{|c|}{ Fruit fly control scenarios } & \multirow{2}{*}{$\begin{array}{l}\text { Trigger number for } \\
\text { establishing an ERZ }\end{array}$} & \multirow{2}{*}{$\begin{array}{l}\text { Calculated Radius of } \\
\text { the ERZ } \\
3200 \mathrm{~m}\end{array}$} & \multirow{2}{*}{$\begin{array}{l}\text { Time to remove the } \\
\text { ERZ (reinstate the } \\
\text { PFA) } \\
14 \text { weeks }\end{array}$} \\
\hline B. tryoni & New Zealand & & & \\
\hline & Australia_urban areas & 3 flies in two weeks & $3200 \mathrm{~m}$ & 61.6 weeks \\
\hline & Australia_-production areas & 1 fly & $7800 m$ & 61.6 weeks \\
\hline \multirow[t]{3}{*}{ B. dorsalis } & New Zealand & 1 fly & $5480 m$ & 6 weeks \\
\hline & California_urban areas & 1 fly & $5080 m$ & 228 weeks \\
\hline & California_-production areas & $1 \mathrm{fly}$ & $6400 m$ & 312 weeks \\
\hline
\end{tabular}

production (2000 m grid) areas in California, I found the predicted population sizes at the trigger point were 32 and 128 male flies respectively.

Using Eq. 5, values for the number of male flies outside a trapping area $\left(N_{r}\right)$ can be calculated over a range of increasing distances from the population epicentre $\left(P_{r}\right)$. I found that there are unlikely to be any male flies more than $1370 \mathrm{~m}$ from the epicentre. The radius of the $E R Z$ for two generations of $B$. dorsalis would then equal four times this radius or $5480 \mathrm{~m}$. I repeated the same calculations for populations in urban and production areas in California containing 32 and 128 male flies and found potential distributions of $1270 \mathrm{~m}$ and $1600 \mathrm{~m}$ respectively. Therefore, the radius of the $E R Z$ for two generations of $B$. dorsalis would equal four times these radii or $5080 \mathrm{~m}$ for 1000 -m grids and $6400 \mathrm{~m}$ for 2000 -m grids.

\section{Criteria for removing an export restriction zone for $B$. dorsalis}

From the response parameters and the biological description of $B$. dorsalis provided above, I determined the length of trapping periods required to provide a $95 \%$ level of confidence that the area is free of a breeding population of B. dorsalis in New Zealand and California, USA. Once the area is declared free of $B$. dorsalis, the ERZ can be removed from. The variables required are as follows:

- New Zealand uses a surveillance grid to reinstate a PFA for $B$. dorsalis which provides a trap density (Td) of 0.142 traps per hectare.

- For urban areas in California, the minimum trap density (Td) of the surveillance grid to reinstate a PFA for B. dorsalis is 0.029 traps per hectare.

- For production areas in California, the minimum trap density $(\mathrm{Td})$ of the surveillance grid to reinstate a PFA for B. dorsalis is 0.022 traps per hectare.

- A median estimate of the effective sampling area

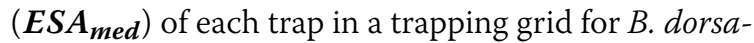
lis using the methyl eugenol bait is 9 ha.
I applied Eq. 6 to these variables for the New Zealand data and plotted the probabilities of detecting two male flies in ERZ over more than one trapping period. I found that 1.4 trapping periods or 6 weeks of no-fly detections would provide at $>95 \%$ probability that a breeding fly population ( $>2$ male flies) no longer exists in the area.

I repeated the calculations for urban and commercial production areas of California, USA, and found trapping periods of 57 (228 weeks) and 78 (312 weeks) respectively.

\section{Summary of results from calculations}

The results for the calculations for the response criteria for B. tryoni and B. dorsalis are summarised in Table 3.

\section{Discussion}

Suckling et al. (2016) reviewed 211 response programmes against 17 species of fruit flies in 31 countries to investigate factors affecting successful eradication outcomes. The authors noted that "Eradication success generally required the combination of several tactics applied on an area-wide basis. Because the likelihood of eradication declines with an increase in the area infested, it pays to invest in effective surveillance networks that allow early detection and delimitation while invading populations are small, thereby greatly favouring eradication success".

In this paper, I have attempted to construct decision criteria that countries can employ to design surveillance networks that enable them to more effectively manage potential and actual fruit fly outbreaks. The first criterium centres on the decision as to whether a fruit fly outbreak has occurred and an area of control or ERZ needs to be instated, what is referred to as the "trigger". The model I designed to estimate an appropriate outbreak "trigger" relies on several pieces of information, two of which come with a degree of uncertainty. The first of these is a measure of lure trap efficacy referred to as the effective sampling area (ESA). It is both a translation coefficient between population density and insect captures in a single trap, and the area by which we need to 
divide trap catch in order to obtain an estimate of population density (Turchin and Odendaal 1996). Estimates for a trap and lure ESA for each fruit fly were based on records of fruit fly release and recapture rates into areas that contain trapping grids of a known density (see Additional file 1). The effectiveness of any trapping system will likely be affected by local environmental factors along with differences in trial design, and therefore the calculated estimates for each trap and lure ESA for each fruit fly ranged considerably. I applied the median ESA value to all calculations. However, undertaking more focused and controlled fruit fly release and recapture experiments would be expected to provide more accurate estimates of ESA values under different trapping configurations and environmental conditions.

The second important factor are the estimates of the breeding population size of each fruit fly species. An extensive literature review by the authors was only able to identify one published estimate for establishment density, namely that for B. tryoni provided by Meats (1998b). For all other fruit flies, I had to rely on a very conservative number for the adult fly density provided by Baker et al. (1990) of 3 flies per hectare. As with ESA, undertaking carefully designed experiments to better estimates of establishment density for different fruit fly species would enable more accurate estimates of trigger numbers to be developed. While these trigger numbers could be provided as a probability distribution given a certain incipient population size, a discrete number is required for use in regulatory decision making.

\section{Calculated fruit fly triggers}

I examined the results of applying the trigger model on B. tryoni and B. dorsalis for each country (Table 3), and I found that the trapping arrays employed in surveillance systems for $B$. dorsalis may not be sensitive enough to provide confidence that an outbreak has not already occurred when the first fly is captured. This finding contrasts with the surveillance trapping arrays in New Zealand and urban areas of Australia for $B$. tryoni where my model would allow for a further two flies to be captured after the first before the trigger for an outbreak was reached. In reality, all of the countries included in my study respond to the first fly captured by increasing their trapping density around the first find location. In the case of New Zealand, the trapping density is increased significantly from 0.065 traps per hectare to 0.283 traps per hectare for B. tryoni and from 0.0072 traps per hectare to 0.141 traps per hectare for $B$. dorsalis. These increases in trapping density increase the estimated trigger numbers for $B$. tryoni and $B$. dorsalis from 3 to 4 flies and 1 to 4 flies (over a two-week period) respectively. Additionally, this increase in estimated trigger numbers from increasing trapping density occurs for $B$. dorsalis in California.

An increase in trapping density would seem to be justified for surveillance trapping densities that result in outbreak trigger numbers of only one fly. Where surveillance trapping densities result in outbreak trigger numbers greater than one, countries would be justified in not investing in further trapping until the outbreak trigger had been reached. However, the investment in further trapping may still be cost effective if the increased trigger sensitivity reduced the number of false positives (false declarations of an outbreak) which can incur considerable economic impacts.

\section{Calculated sizes of export restriction zones}

When fruit fly outbreaks currently occur, importing countries can require differently sized export restrictions zones from which export of all host material may be restricted. In most cases the size of these zones is independent of the fruit fly species detected, meaning they may be established based on the worst-case fruit fly outbreak scenario. A considerable reduction in the economic costs of export restrictions zones could be achieved if these zones were sized based on speciesspecific fruit fly biology and trapping effectiveness. Reviews of recorded dispersal distances of $B$. tryoni by Dominiak (2012) and Dominiak and Fanson (2020) found that the Australian code of practice requirement of a $15 \mathrm{~km}$ radius ERZ was likely to be more than three times larger than required.

The application of the criteria developed in this paper for determining the size of export restrictions zones offers countries the opportunity to consider the costs of increasing or decreasing the density of their surveillance trapping verses the costs associated with a larger or smaller export restrictions zone. An increase in the investment in higher density surveillance trapping would be rewarded with lower costs associated with a smaller export restrictions zone. For instance, if New Zealand were to increase the density of surveillance traps for B. dorsalis from a $1200-\mathrm{m}$ grid to an $800-\mathrm{m}$ grid, the pay-off would be a reduction in the radius of any resulting ERZ from $5480 \mathrm{~m}$ to $4680 \mathrm{~m}$, equating to as much as 2,500 hectares of orchard production not requiring treatment for export. As was noted in a report on the financial impact of a fruit fly incursion into New Zealand (Kiwifruit Vine Health 2014), a reduction in the size of an ERZ from 80 to $15 \mathrm{~km}$ resulted in an estimated reduction in market economic impacts of around NZ\$ 200 million and a reduction in total economic impacts of around NZ\$ 350 million. 


\section{Calculated periods to remove the export restriction zone} The results achieved from applying the criteria developed in this paper for the period required to once again declare fruit fly freedom and remove any ERZ were mixed. Where trapping densities were high, such as is the case with the New Zealand response system, the criteria could be used to reduce the period required before normal trade could resume. Where trapping densities are low my model results in excessively long periods to achieve the reinstatement of fruit fly freedom. It is expected that an investment in increasing trapping densities should result in a pay-off of a timelier removal of trade restrictions. However, other factors would be expected to play a role in determining this period for low trapping densities. For example, it may be expected that over extended periods any underlying population of fruit flies would increase in size, making it more likely to be detected by the surveillance system. However, Papadopoulos et al. (2013) reported that under lower density trapping scenarios, detections of fruit flies may arise from low density populations that remain at undetectable levels, sometimes for years. I recognise that this may be possible under some environmental conditions. But it is considered less likely that a fruit fly population can exist in a balanced, stable state at a very low level over such an extended period in environments where they should flourish (Suckling et al. 2016). Additionally, it should be noted that where trapping periods are interrupted by winter and the fruit fly species in question over-winters in the adult life stage, the minimum requirement of a single generation would not be necessary if winter conditions ensure no adults are present when climatic conditions become suitable for trapping once more.

\section{Conclusion}

Models have been developed that can be used to estimate the criterial parameters of any successful surveillance and response system. These models rely primarily on fruit fly biology and the effectiveness surveillance trapping systems. While the advice for each of these factors has been provided as discrete and independent outputs, they are derived from the application of a model using research-generated input data that has varying degrees of variability and uncertainty. Where the data available for model inputs has included a range of values for biological variability, conservative ("worst case") point estimates have been used in some cases. Thus, the outputs of the model are conservative in nature and support somewhat precautionary risk management decisions. As such, the use of these criteria should be considered as conservative guidance.
The adoption internationally of a standard set of criteria for establishing a control system and responding to fruit fly outbreaks would provide considerable economic benefits to international trade. Such criteria would enable countries to make more informed cost-benefit decisions on the level of investment in fruit fly control systems that better reflects the economic risks fruit flies represent to their economy. Also, these criteria would create more confidence in the importing country that imported produce is not infested with fruit fly. Additionally, agreed criteria would encourage research more focused on gaining greater confidence in the parameters of the model such as fruit fly breeding population sizes and ESA values for surveillance systems.

\section{Supplementary Information}

The online version contains supplementary material available at https://doi. org/10.1186/s43170-021-00043-w.

Additional file 1. Calculating the Effective sampling area.

\section{Acknowledgements}

Many thanks go to John Kean, Bernie Dominiak, Roger Vargas, Andrew Robinson, Pat Gomes, Nick Manoukis, Alan Meats and Todd Shelly for reviewing and providing valuable guidance and input into earlier versions of this work. Special thanks to those within the New Zealand Ministry for Primary Industries who provided support and advice, especially Jo Berry, and to Bernie Dominiak who provided invaluable feedback on this manuscript.

\section{Authors' contributions}

Model design and development.

Funding

By employer.

Availability of data and materials

Supplementary file provided.

\section{Declarations}

Ethics approval and consent to participate

Not applicable.

Consent for publication

Consent obtained and granted.

Competing interests

The authors declare that they have no competing interests.

Received: 18 October 2020 Accepted: 1 June 2021

Published online: 15 June 2021

\footnotetext{
References

Acosta H, White P. Atlas of Biosecurity Surveillance, May 2011. Ministry of Agriculture and Forestry, Wellington, New Zealand. 2011.

Baker RT, Cowley JM, Harte DS, Frampton ER. Development of a maximum pest limit for fruit flies (Diptera: Tephritidae) in produce imported into New Zealand. J Econ Entomol. 1990;83:13-7.

Barclay HJ, Hargrove JW. Probability models to facilitate a declaration of pest-free status, with special reference to tsetse (Diptera: Glossinidae) Bull Entomol Res. 2005;95:1-11.
} 
Bateman MA. The ecology of fruit flies. Annu Rev Entomol. 1972;17:493-518. Biney K, Agarwal ML. Comparative biology of three Bactrocera species (Diptera: Tephritidae: Dacinae). Shashpa. 2005;12(2):93-8.

Chiu HT. Movements of Oriental fruit flies in the field. Chin J Entomol. 1983:3(2):93-102.

Clarke AR, Dominiak BC. Positive correlation of male and female Bactrocera tryoni (Froggatt) (Diptera: Tephritidae) catches in orange-ammonia traps. Gen Appl Entomol. 2012;39:9-14.

Clarke AR, Armstrong KF, Carmichael AE, Milne JR, Roderick GK, Yeates DK. Invasive phytophagous pests arising through a recent tropical evolutionary radiation: The Bactrocera dorsalis complex of fruit flies. Annu Rev Entomol. 2005:50:293-319.

Clarke AR, Powell KS, Weldon CW, Taylor PW. The ecology of Bactrocera tryoni (Diptera: Tephritidae): what do we know to assist pest management? Ann Appl Biol. 2011;158:26-54.

COP. Australia's fruit fly code of practice. Subcommittee on Domestic Quarantine and Market Access, Canberra. 2014.

Dominiak BC. Review of dispersal, survival, and establishment of Bactrocera tryoni (Diptera: Tephritidae) for quarantine purposes. Ann Entomol Soc Am. 2012;105:434-46.

Dominiak BC, Fanson BG. Revised quarantine distances for domestic and international trading Queensland fruit fly. 9th International Symposium on Fruit Flies of Economic Importance, Bangkok, Thailand, 12-14 May, 2014.

Dominiak BC, Fanson BG. Current quarantine and suspension distances are excessive for incipient populations of Queensland fruit fly (Bactrocera tryoni (Froggatt)) (Diptera: Tephritidae) in southern New South Wales Australia. Crop Prot. 2020;138:105341

Dominiak BC, Mapson R. Revised distribution of Bactrocera tryoni in eastern Australia and effect on possible incursions of Mediterranean fruit fly: development of Australia's eastern trading block. J Econ Entomol. 2017;110(6):2459-65.

Dominiak BC, Worsley PM, Nicol H. Release from a point source and dispersal of sterile Queensland fruit fly (Bactrocera tryoni (Froggatt)) (Diptera: Tephritidae) at Wagga Wagga. Plant Prot Q. 2013;28(4):120-5.

Dominiak BC, Wiseman B, Anderson C, Walsh B, McMahon M, Duthie R. Definition of and management strategies for areas of low pest prevalence for Queensland fruit fly Bactrocera tryoni Froggatt. Crop Prot. 2015;72:41-6.

Doorenweerd C, Leblanc L, Norrbom AL, Jose MS, Rubinoff D. A global checklist of the 932 fruit fly species in the tribe Dacini (Diptera, Tephritidae). ZooKeys. 2018:730:17-54. https://doi.org/10.3897/zookeys.730.21786.

Drew RAl, Romig MC. Tropical fruit flies (Tephritidae: Dacinae) of South-East Asia: Indomalaya to North-West Australasia. In Tropical fruit flies (Tephritidae: Dacinae) of South-East Asia: Indomalaya to North-West Australasia. 2013; 653 pp.

EPPO. Bactrocera dorsalis. Data sheets on quarantine pests CAB International; Wallingford, UK; 2009

Fanson BG, Sundaralingam S, Jiang L, Dominiak BC, D'Arcy G. A review of 16 years of quality control parameters at a mass-rearing facility producing Queensland fruit fly, Bactrocera tryoni. Entomol Exp Appl. 2014;151:152-9.

FAO. Establishment of pest free areas for fruit flies (Tephritidae). International Standard for Phytosanitary Measures No. 43. Rome. Published by FAO on behalf of the Secretariat of the International Plant Protection Convention (IPPC). 2016; 56 pp.

Fletcher BS. The ecology of a natural population of the Queensland fruit fly, Dacus tryoni VI. Seasonal changes in fruit fly numbers in the areas surrounding the orchard. Aust J Zool. 1974;22:189-202.

Froerer KM, Peck SL, McQuate GT, Vargas RI, Jang EB, McInnis DO. LongDistance Movement of Bactrocera dorsalis (Diptera: Tephritidae) in Puna, Hawaii: How far can they go? Am Entomol. 2010;56(2):88-94.

Garcia FRM. Fruit fly: Biological and ecological aspects. In: Bandeira RRC. Current Trends in Fruit Fly Control on Perennial Crops and Research Prospects. Transworld Research Network. 2009; pp 1-35. ISBN-13: 978-8178954110

Hancock DL, Hamacek EL, Lloyd AC, Elson-Harris MM. The Distribution and Host Plants of Fruit Flies (Diptera: Tephritidae) in Australia. Queensland Department of Primary Industries. 2000. ISSN 0727e6273.

Kiwifruit Vine Health. Financial impact of a fruit fly incursion to New Zealand's kiwifruit industry; 2014; 6. www.kvh.org.nz.
Kean J. The effective sampling area of traps: estimation and application. In: Beresford RM, Froud KJ, Kean JM, Worner SP. New Zealand Plant Protection Society. The plant protection data toolbox. New Zealand Plant Protection Society Incorporated. 2015a; 176.

Kean J. Meta-analysis, validation and application of fruit fly development times. New Zeal Plant Prot Society. 2015b;68:44-53.

MacFarlane JR, East RW, Drew RAI, Betlinski GA. Dispersal of irradiated Queensland fruit flies, Dacus tryoni (Froggatt) (Diptera: Tephritidae), in southeastern Australia. Aust J Zool. 1987:35(3):275-81.

Meats A. Predicting or interpreting trap catches resulting from natural propagules or releases of sterile fruit flies. An actuarial and dispersal model tested with data on Bactrocera tryoni. Gen Appl Entomol. 1998a;28:29-38.

Meats A. The power of trapping grids for detecting and estimating the size of invading propagules of the Queensland fruit fly and risks of subsequent infestation. Gen Appl Entomol. 1998b;28:47-55.

Meats A. Fruit fly detection programs: the potentials and limitations of trap arrays. In: Shelly TE, Epsky N, Jang EB, Reyes-Flores J, Vargas R, eds. Trapping and the Detection, Control, and Regulation of Tephritid Fruit Flies. Springer; 2014. pp 643.

Meats A, Clift AD. Zero catch criteria for declaring eradication of tephritid fruit flies: the probabilities. Aust J Exp Agric. 2005;45:1335-40.

Meats A, Edgerton JE. (2008) Short- and long-range dispersal of the Queensland fruit fly, Bactrocera tryoni and its relevance to invasive potential, sterile insect technique and surveillance trapping. Aust J Exp Agric. 2008:48:1237-45.

Meats A, Clift AD, Robson MK. Incipient founder populations of Mediterranean and Queensland fruit flies in Australia: the relation of trap catch to infestation radius and models for quarantine radius. Aust J Exp Agric. 2003:43:407-17.

MPI. MPI Standard: Fruit Fly Response (Field Operations). New Zealand Ministry for Primary Industries. 2014: 31 pp.

Papadopoulos NT, Plant RE, Carey JR. From trickle to flood: the largescale, cryptic invasion of California by tropical fruit flies. Proc R Soc B. 2013;280:20131466.

Plant Health Australia. The Australian handbook for the identification of fruit flies. Version 2.1. Plant Health Australia. Canberra, ACT; 2016.

Qin Y, Paini DR, Wang C, Fang Y, Li Z. Global establishment risk of economically important fruit fly species (Tephritidae). PLoS ONE. 2015;10(1):e0116424. https://doi.org/10.1371/journal.pone.0116424.

Quilici S, Donner P. Analysis of exotic fruit fly trapping networks. EPPO Bull. 2012:42:102-8

Raghu S, Clarke AR, Drew RAl, Hulsman K. Impact of habitat modification on the distribution and abundance of fruit flies (Diptera: Tephritidae) in Southeast Queensland. Popul Ecol. 2000;42:153-60.

Royer JE. Responses of fruit flies (Tephritidae: Dacinae) to novel male attractants in north Queensland Australia, and Improved Lures for Some Pest Species Austral. Entomology. 2015;54:411-26.

RSPM 17. Guidelines for the establishment, maintenance and verification of fruit fly pest free areas in North America. NAPPO Regional Standards for Phytosanitary Measures. The Secretariat of the North American Plant Protection Organization; 2010; 12 pp.

Schutze MK, Aketarawong N, Amornsak W, Armstrong KF, Augustinos AA. Synonymization of key pest species within the Bactrocera dorsalis species complex (Diptera: Tephritidae): taxonomic changes based on a review of 20 years of integrative morphological, molecular, cytogenetic, behavioural and chemoecological data. Syst Entomol. 2015;40(2):456-71.

Stringer LD, Kean JM, Beggs JR, Suckling DM. Management and eradication options for Queensland fruit fly. Popul Ecol. 2017;59:259-73.

Suckling DM, Kean JM, Stringer LD, Cáceres-Barrios C, Hendrichs J, ReyesFloresg J, Dominiak BC. Eradication of tephritid fruit fly pest populations: outcomes and prospects. Pest Manag Sci. 2016;72:456-65.

Tobin PC, Berec L, Liebhold AM. Exploiting Allee effects for managing biological invasions. Ecol Lett. 2011;14:615-24.

Turchin P, Odendaal FJ. Measuring the effective sampling area of a pheromone trap for monitoring population density of southern pine beetle (Coleoptera: Scolytidae). Environ Entomol. 1996;25:582-8.

USDA APHIS. PPQ action plan: Oriental fruit fly, Bactrocera dorsalis Hendel (synonym = Dacus dorsalis Hendel). United States Department of Agriculture, Animal and Plant Health Inspection Service, Plant Protection and Quarantine, Cooperating State Departments of Agriculture. 1989; 56 pp. 
Vargas RI, Carey JR. Comparative survival and demographic statistics for wild oriental fruit fly, Mediterranean fruit fly, and melon fly (Diptera: Tephritidae) on papaya. J Econ Entomol. 1990;83(4):1344-9.

Vargas RI, Walsh WA, Kanehisa D, Stark JD, Nishida T. Comparative demography of three Hawaiian fruit flies (Diptera: Tephritidae) at alternating temperatures. Ann Entomol Soc Am. 2000;93:75-81.

Vargas RI, Piñero JC, Leblanc L. An overview of pest species of Bactrocera fruit flies (Diptera: Tephritidae) and the integration of biopesticides with other biological approaches for their management with a focus on the pacific region. Insects. 2015;6:297-318.

Weldon CW. Dispersal and mating behaviour of Queensland fruit fly, Bactrocera tryoni (Froggatt) (Diptera: Tephritidae): implications for population establishment and control. Ph.D. Thesis, University of Sydney; 2005. http://ses.library.usyd.edu.au/handle/2123/700.

Yonow T, Zalucki MP, Sutherst RW, Dominiak BC, Maywald GF, Maelzer DA,

Kriticos DJ. Modelling the population dynamics of the Queensland fruit

fly, Bactrocera (Dacus) tryoni: a cohort-based approach incorporating the effects of weather. Ecol Model. 2004;173:9-30.

\section{Publisher's Note}

Springer Nature remains neutral with regard to jurisdictional claims in published maps and institutional affiliations.
Ready to submit your research? Choose BMC and benefit from:

- fast, convenient online submission

- thorough peer review by experienced researchers in your field

- rapid publication on acceptance

- support for research data, including large and complex data types

- gold Open Access which fosters wider collaboration and increased citations

- maximum visibility for your research: over 100M website views per year

At $B M C$, research is always in progress.

Learn more biomedcentral.com/submissions 